\title{
Molecular Gas Electron Distribution Function with Space and Time Variation
}

\section{Manuel Garcia}

RECEIVED

JUN 271996

OSTI

\section{MASTER}

May 1, 1995

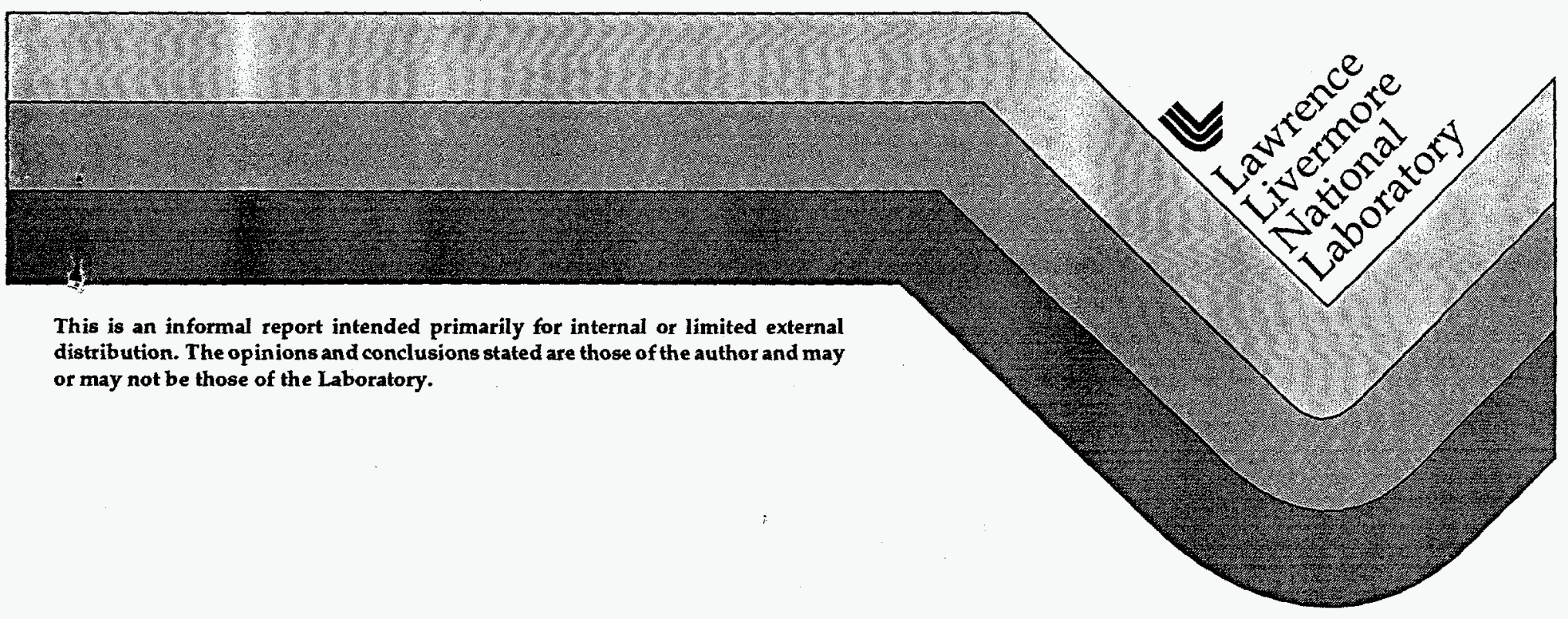




\section{DISCLAIMER}

This report was prepared as an account of work sponsored by an agency of the United States Government. Neither the United States Government nor any agency thereof, nor any of their employees, makes any warranty, express or implied, or assumes any legal liability or responsibility for the accuracy, completeness, or usefulness of any information, apparatus, product, or process disclosed, or represents that its use would not infringe privately owned rights. Reference herein to any specific commercial product, process, or service by trade name, trademark, manufacturer, or otherwise does not necessarily constitute or imply its endorsement, recommendation, or favoring by the United States Government or any agency thereof. The views and opinions of authors expressed herein do not necessarily state or reflect those of the United States Government or any agency thereof. 


\section{DISCLAMERR}

Portions of this document may be illegible in electronic image products. Images are produced from the best available original document. 


\section{Molecular Gas Electron Distribution Function with Space and Time Variation}

\section{Manuel Garcia}

Lawrence Livermore National Laboratory

An approximate, electron energy distribution function, $f(\varepsilon, x, t)$, is obtained for the case of a slightly ionized gas with inelastic electron-molecule collisions, and for an external electric field with both spatial and temporal variation, $E(x, t)$. This analysis yields an approximate solution for the isotropic leading term of the spherical harmonic expansion of the Boltzmann equation. This result is considered valid when the electric field has a characteristic frequency $|\omega|<v_{\mathrm{m}}$, and a characteristic length scale $\left|\lambda_{\mathrm{e}}\right|>\lambda_{\mathrm{m}}$, where these parameters are defined as:

$$
\begin{aligned}
\omega(x, t) & =(3 / 2)(\partial / \partial t) \ln \left[|E(x, t)|+k T / e \lambda_{m}\right] \\
1 / \lambda_{e}(x, t) & =(1 / 4)(\partial / \partial x) \ln \left[|E(x, t)|+k T / e \lambda_{m}\right]
\end{aligned}
$$

and where $v_{m}$ and $\lambda_{m}$ are respectively the electronmolecule elastic collision frequency and mean free path at thermal energy. There are no other limiting assumptions made about gas mixture composition, crosssection shapes, or electric field space and time behavior. An interesting feature of this analytical distribution function is its explicit dependence on both the magnitude of the field, $E(x, t)$, and its gradients, $\omega(x, t)$ and $\lambda_{e}(x, t)$. Example distribution functions are shown for an idealized $\mathrm{N}_{2}$-like gas. These examples include electric fields with ramp or sinusoidal temporal variations, or an exponential spatial decay. An application of the model shows the variation in both space and time of the average electron energy, $\varepsilon(x, t)$, in the $\mathrm{N}_{2}$-like gas at 1 Torr when $\mathrm{E} / \mathrm{N}$ is a $100 \mathrm{Td}, 500 \mathrm{kHz}$ oscillation with an exponential decay along $x / \lambda_{E}$ where $\lambda_{E}$ is chosen equal to $\lambda_{m}$. 


\section{Introduction}

The desire for improved control over electric discharge phenomena in a wide variety of scientific, technological, manufacturing, and waste processing activities spurs the development of non-equilibrium, non-uniform, and time dependent models. This paper addresses the situation of a slightly ionized, uniform gas with a space and time varying electric field, and in which inelastic collisions occur. The purpose here is to present a reasonably consistent, and reasonably accessible analytical result for the electron kinetics in a gas discharge regime of technological interest.

This paper will be structured as follows. First, the analytical result for the logarithmic derivative in energy of the electron distribution function is stated. Then, a discussion of the derivation is given. Examples of the solution are shown for an idealized nitrogenlike gas where a uniform electric field ramps in time between static conditions, and then for sinusoidal behavior. Further examples show the effect of a static electric field that decays exponentially with distance. Finally, the combined effect of field gradients in space and time is demonstrated by mapping out the average electron energy in the model gas for a field with sinusoidal temporal variation and exponential spatial decay.

\section{Analytical Result}

The distribution function of electron energies is denoted as $f(\varepsilon, x, t)$, where electron kinetic energy $\varepsilon$ is expressed in units of $e V$, and where the distribution function is normalized as:

$$
\int f(\varepsilon, x, t) \sqrt{ } \varepsilon d \varepsilon=1
$$

The function $B(\varepsilon, x, t)$ is defined as:

$$
B(\varepsilon, x, t)=-(\partial / \partial \varepsilon) \ln [f(\varepsilon, x, t)]
$$

and the distribution function is then given by: 


$$
f(\varepsilon, x, t)=\frac{e}{\int_{0}^{\infty} e^{-\int_{0}^{\varepsilon} B(\varepsilon, x, t) d \varepsilon}}
$$

The logarithmic slope $B(\varepsilon, x, t)$ is given by:

$$
B(\varepsilon, x, t)=\frac{\sqrt{(L+\mu)^{2}+\left(\frac{4 Q i}{\varepsilon Q_{m}}\right)\left(U+\mu \frac{k T}{e}\right)}+(L+\mu)}{2\left(U+\mu \frac{k T}{e}\right)}
$$

The terms used in $B(\varepsilon, x, t)$ are as follows:

$L(\varepsilon, x, t)=\left[\frac{\omega}{2 v_{m}}+6\left(\frac{\lambda_{m}}{\lambda_{g}}\right)\left(\frac{E / N}{3 \varepsilon Q_{m}}+\frac{\lambda_{m}}{\lambda_{e}}\right)-\lambda_{m}^{2} \frac{\partial}{\partial x}\left(\frac{1}{\lambda_{e}}\right)\right] * \Phi$

$U(\varepsilon, x, t)=\left[b(\varepsilon, x, t)+\frac{E / N}{3 Q_{m}}\left(\frac{\lambda m}{\lambda_{\mathrm{e}}}\right)\right] * \Phi$ 


$$
\begin{aligned}
& \Phi(\varepsilon, \mathbf{x}, \mathbf{t})=H\left(\varepsilon_{\mathbf{m}}(\varepsilon, \mathbf{x}, \mathbf{t})-\varepsilon\right) \\
& \mathrm{H}=\text { Heaviside Unit Step Function, } \\
& \varepsilon_{m}(\varepsilon, x, t)=\frac{E(x, t) \lambda_{m}}{\left[\lambda_{m} / \lambda_{e}+3(\mu \mathrm{kT} / \mathbf{e}) /\left(E \lambda_{m}\right)\right]} \\
& \text { @ } \lambda_{\mathrm{m} / \lambda_{\mathrm{e}}}<-3(\mu \mathrm{kT} / \mathrm{e}) /\left(\mathrm{E} \lambda_{\mathrm{m}}\right) \\
& \varepsilon_{m}(\varepsilon, \mathbf{x}, \mathbf{t})=\infty \\
& @ \lambda_{\mathrm{m}} / \lambda_{\mathrm{e}} \geq-3(\mu \mathrm{kT} / \mathrm{e}) /\left(\mathrm{E} \lambda_{\mathrm{m}}\right) \\
& b(\varepsilon, x, t)=[E(x, t) / N]^{2} /\left(3 \varepsilon Q_{m}^{2}\right) \\
& \frac{1}{\lambda e(x, t)}=\frac{1}{4} \frac{\partial}{\partial x} \ln \left(\frac{E(x, t)}{N}\right) \\
& \lambda_{\mathrm{m}}(\varepsilon)=1 /\left(\mathrm{NQ} \mathrm{Q}_{\mathrm{m}}(\varepsilon)\right)
\end{aligned}
$$

and the following:

$$
\omega(x, t)=3 / 2 * 1 /[E / N] *(\partial / \partial t)[E / N]
$$

$E(x, t)=$ electric field over space \& time, in the form:

$$
\begin{gathered}
E(x, t)=|E(x, t)|+k T / e^{*} Q_{m}(k T / e) * N \\
E(x, t)=\text { any imposed external field, } \\
v_{m}(\varepsilon)=N * Q_{m} * \sqrt{ } 2 e \varepsilon / m
\end{gathered}
$$




$$
\begin{aligned}
& Q_{m}(\varepsilon)=\text { electron-molecule momentum transfer cross section } \\
& \begin{array}{l}
Q_{i}(\varepsilon)=\text { electron-molecule net inelastic cross section } \\
\begin{array}{l}
\mu=2 \mathrm{~m} / \mathrm{M} \quad \mathrm{m}=\text { electron mass } \\
\mathrm{M}=\text { molecule mass }
\end{array} \\
\mathrm{kT} / \mathrm{e}=\text { gas temperature in } \mathrm{eV} \\
\mathrm{N}=\text { gas mixture number density, a constant }
\end{array}
\end{aligned}
$$

For a gas mixture:

$\delta_{\mathbf{s}}=$ fractional concentration of species $\mathbf{s}$

$$
\begin{aligned}
& \underset{\mathrm{m}}{\mathrm{Q}(\varepsilon)}=\sum_{\mathrm{s}} \delta \underset{\mathrm{s}}{-\mathrm{Q}} \mathrm{\textrm {ms }} \\
& \mathbf{m}=\text { momentum transfer }
\end{aligned}
$$

$$
\begin{aligned}
& \underset{i}{Q}(\varepsilon)=\sum_{s} \sum_{i} \sum_{j} \delta \delta_{s i}-\underset{i \text { s ij }}{Q(\varepsilon)} \\
& 1=\text { inelastic process (sum) with transition indices: } \\
& 1=\text { index of initial energy level } \\
& \mathrm{j}=\text { index of final energy level }
\end{aligned}
$$
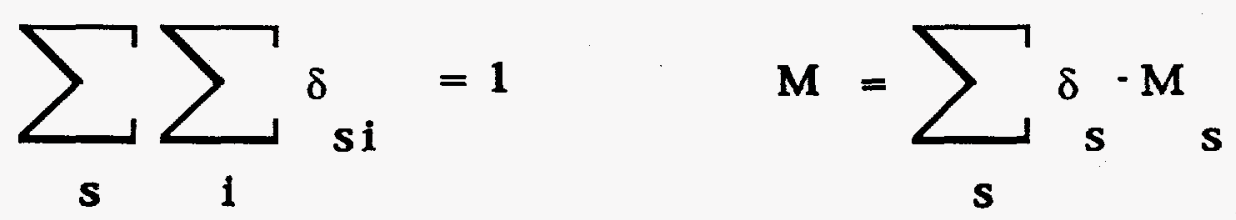


\section{Analytical Procedure}

This analysis begins with a two term expansion of the electron velocity distribution function in a Boltzmann equation with three collisional effects: recoil and thermal agitation during elastic electron-molecule encounters, and inelastic collisions. ${ }^{1}$

$\frac{\partial f_{0}}{\partial t}+\frac{v}{3} \frac{\partial f_{1}}{\partial x}-\frac{e E_{x}(x, t)}{m} \frac{1}{3 v^{2}} \frac{\partial}{\partial v}\left(v^{2} f_{1}\right)=$
$\frac{1}{2 v^{2}} \frac{\partial}{\partial v}\left[v^{2}\left(2 \frac{m}{M}\right)\left(N Q_{m} v_{r}\right)\left(\frac{k T}{m} \frac{\partial f_{0}}{\partial v}+v f_{0}\right)\right]+S_{I}(v)$

$\frac{\partial f_{1}}{\partial t}+v \frac{\partial f_{0}}{\partial x}-\frac{e E_{x}(x, t)}{m} \frac{\partial f_{0}}{\partial v}=-\left(N Q_{m} v_{r}\right) f_{1}$

$\frac{4 \pi \sqrt{2}}{\left(\frac{m}{e}\right)^{\frac{3}{2}}} \sqrt{\frac{m \varepsilon}{2 e}} \frac{S_{I}(v)}{N}=$

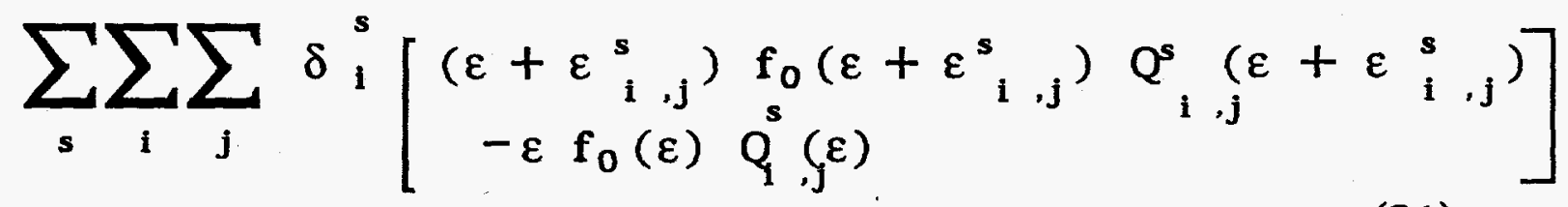

The two term expansion is

$$
f=f_{0}+\cos (\theta) * f_{1}
$$


where $\theta$ is the angle between the electron velocity vector and the field. Coordinate $\mathbf{x}$ is aligned with the field, which is noted by a subscript $x$ on $E$, and $v_{r}$ is the relative electron-molecule velocity. $S_{I}(v)$ is the inelastic collision term, shown in equation (21) as a function of energy.

The $f_{0}$ term of the expansion describes the bulk heating of the electrons by the electric field in an environment dominated by collisions, while the $f_{1}$ term describes the net drift of this electronic swarm along the field and represents the macroscopic current.

The recoil and thermal agitation collision terms transmit a small fraction of an electron's energy to a molecule, this fraction being given by the ratio of the electron to molecule masses. The inelastic term involves the transfer of sufficient energy to initiate rotational, vibrational, electronic, dissociation, and ionization phenomena.

The zeroth and first order velocity distribution equations are transformed to a dependence on electron kinetic energy in units of $\mathrm{eV}$. During this change of parameters the relative velocity between electrons and molecules is ascribed entirely to electron speed. Specifically:

$$
\begin{aligned}
& \varepsilon=m v^{2} / 2 \mathrm{e} \\
& f_{0}(\varepsilon, x, t)=\left[4 \pi \sqrt{ } 2 /(m / e)^{3 / 2}\right] * f_{0}(v, x, t)
\end{aligned}
$$

Equations (19), (20), and (21) are combined into a single expression for $f_{0}$. This equation is divided by $N$ and integrated over energy from 0 to $\varepsilon$. An inelastic cross section is zero below a threshold energy which is at least as large as the energy extracted from the electron during the encounter. For example the cross section for excitation from the 0 to 1 vibrational level in $\mathrm{N}_{2}$ is zero below about $1.4 \mathrm{eV}$, while the energy transferred is about $0.3 \mathrm{eV}$. This fact about the cross sections proves useful in the manipulation of the inelastic collision integrals. The resulting equation is: 


$$
\begin{aligned}
& \sqrt{\frac{m}{2} \mathrm{e}} \frac{1}{\mathrm{~N}} \frac{\partial}{\partial t} \int_{0}^{\varepsilon} \text { fo } \sqrt{\varepsilon} d \varepsilon \\
& +\frac{-1}{3} \frac{E}{N} \varepsilon e^{-v_{m} t} \sqrt{\frac{2 e \varepsilon}{m}} \int_{0}^{t} e^{v_{m} \tau}\left(E \frac{\partial f_{o}}{\partial \varepsilon}-\frac{\partial f_{0}}{\partial x}\right) d \tau \\
& +\frac{1}{3 N} \int_{0}^{\varepsilon} \varepsilon e^{-v_{m}^{t}} \sqrt{\frac{2 e \varepsilon}{m}} \int_{0}^{t} e^{v_{m} \tau} \frac{\partial}{\partial x}\left(E \frac{\partial f_{0}}{\partial \varepsilon}-\frac{\partial f_{0}}{\partial x}\right) d \tau d \varepsilon \\
& +-\sum_{s} \sum_{i} \sum_{j} \delta_{s i} \int_{\varepsilon}^{\varepsilon+\varepsilon_{s i j}} \begin{array}{lllll} 
& & & & \\
& & f_{0} & Q_{s i j} & d \varepsilon
\end{array} \\
& +-\left(\frac{2 \mathrm{~m}}{\mathrm{M}}\right) \varepsilon^{\mathrm{j}} \mathrm{Q}_{\mathrm{m}}\left(\frac{\mathrm{kT}}{\mathrm{e}} \frac{\partial \mathrm{f}_{\mathrm{o}}}{\partial \varepsilon}+\mathrm{f}_{\mathrm{o}}\right)= \\
& \frac{1}{3} \frac{E}{N} \varepsilon e^{-v_{m} t} f_{1}(\varepsilon, x, 0) \\
& +\frac{-1}{3 N} \int_{0}^{\varepsilon} \varepsilon e^{-v} m_{m}^{t} \frac{\partial f_{1}(\varepsilon, x, 0)}{\partial x} d \varepsilon
\end{aligned}
$$

The relationship between $f_{0}$ and $f_{1}$ is:

$$
\frac{\partial \mathrm{f}_{1}}{\partial \mathrm{t}}+v_{\mathrm{m}} \mathrm{f}_{1}=\frac{\mathrm{e} \mathrm{E}}{\mathrm{m}} \sqrt{\frac{2 \mathrm{~m} \varepsilon}{\mathrm{e}}} \frac{\partial \mathrm{f}_{\mathrm{o}}}{\partial \varepsilon}-\sqrt{\frac{2 \mathrm{e} \varepsilon}{\mathrm{m}}} \frac{\partial \mathrm{f}_{\mathrm{o}}}{\partial \mathrm{x}}
$$


The essence of the solution procedure employed here is to make the exponential transform from $f(\varepsilon, x, t)$ to $B(\varepsilon, x, t)$, and then to argue as in the WKB method that the equation for $B(\varepsilon, x, t)$ has a stationary solution. ${ }^{2,3,4} \mathrm{~B}$ is like a local inverse electron temperature and its rate of change is assumed to be negligible over a collision time and mean free path, specifically:

$$
\begin{aligned}
& \left(\varepsilon / 2 \nu_{\mathrm{m}}\right) * \partial \mathrm{B} / \partial \mathrm{t} \rightarrow 0 \\
& \left(\varepsilon \lambda_{\mathrm{m}}\right)^{*} \partial \mathrm{B} / \partial \mathrm{x} \rightarrow 0
\end{aligned}
$$

The resulting equation for $B$ includes the effect of space and time variation of the normalization integral of the distribution function, which is how these variations of the electric field exert their influence.

The mechanics of deriving the equation for $B(\varepsilon, x, t)$ involve: substituting equation (3) into equations (24) and (25) in place of $f_{0}$, and then dividing equation (24) by $f_{0}$ as defined by equation (3). A convenient label for the normalization integral is $C(x, t)$. The result from equation (24) is:

$$
\begin{aligned}
& -\frac{1}{N} \sqrt{\frac{m}{2 e}} \int_{0}^{\varepsilon} \sqrt{\zeta} e^{\int_{\zeta}^{\varepsilon} B(\eta, t) d \eta} \frac{\partial}{\partial t}\left(\int_{0}^{\zeta} B(\eta, t) d \eta\right) d \zeta
\end{aligned}
$$

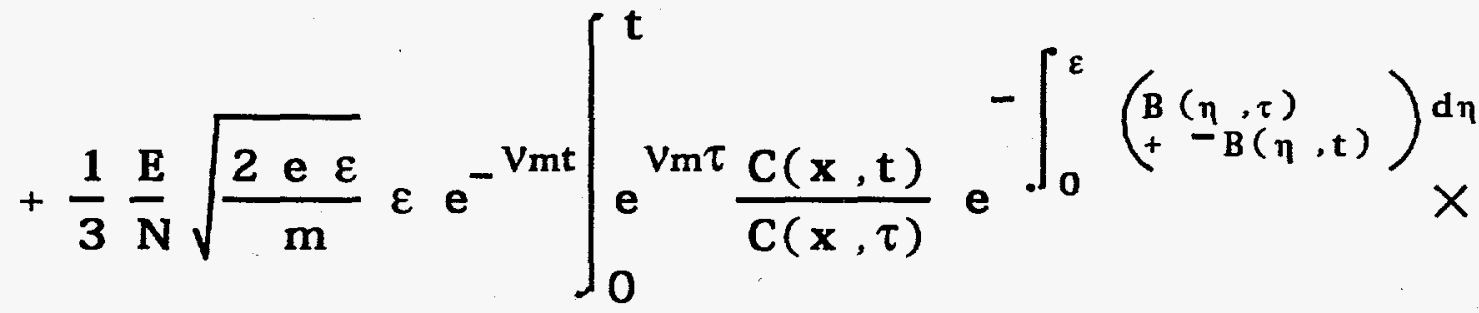

$$
\begin{aligned}
& {\left[E B(\varepsilon, x, \tau)-\frac{\partial}{\partial x}\left(\int_{0}^{\varepsilon} B(\eta, \tau) d \eta\right)\right] d \tau+}
\end{aligned}
$$




$$
\begin{aligned}
& +\frac{1}{3 N} \int_{0}^{\varepsilon} \int_{0}^{t} \sqrt{\frac{2 e \zeta}{m}} \zeta e^{-V_{m}(t-\tau)} \frac{\text { fo }(\zeta, x, \tau)}{\text { fo }(\varepsilon, x, t)} \times
\end{aligned}
$$

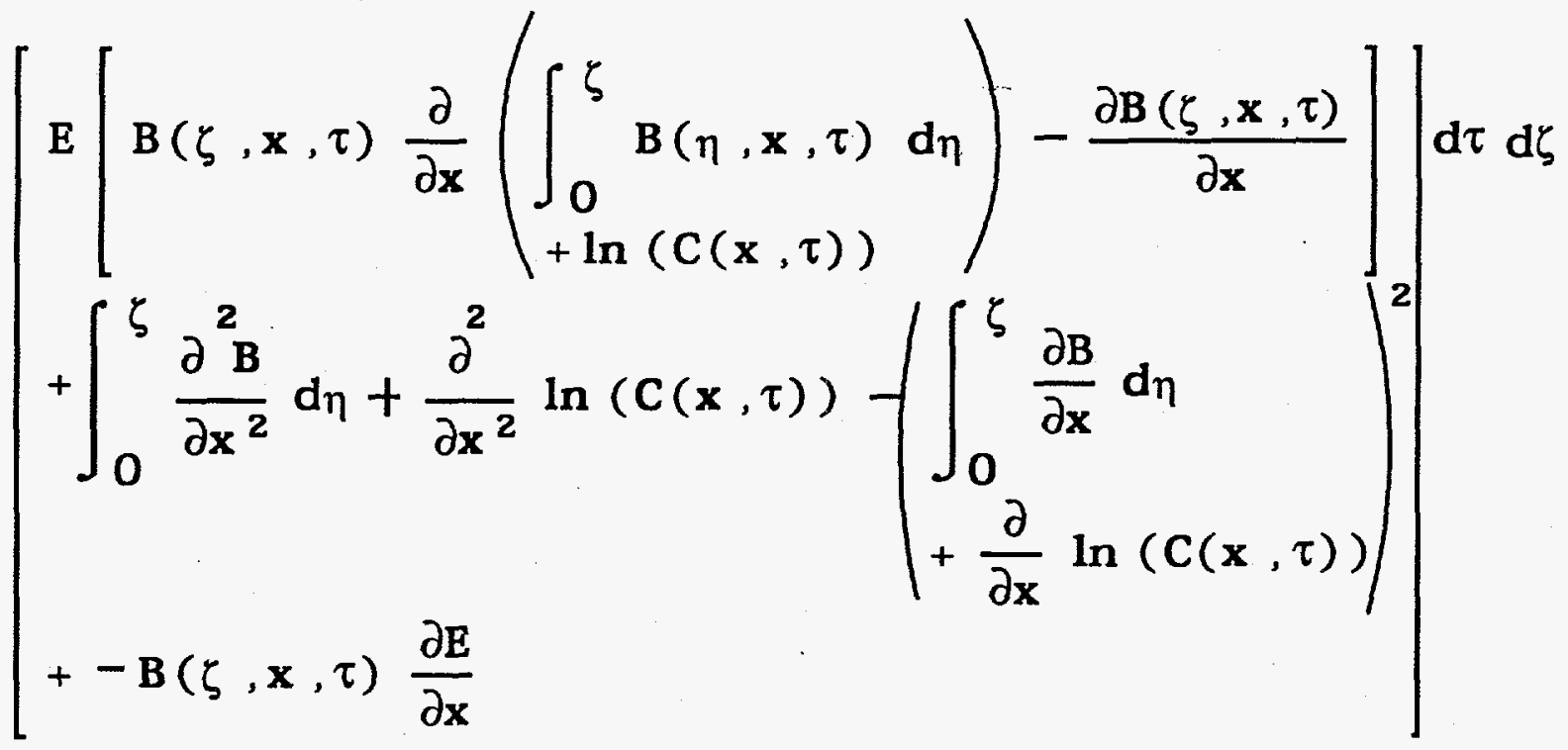

$$
\begin{aligned}
& -\sum_{s} \sum_{i} \sum_{j} \delta_{s i} \int_{\varepsilon}^{\varepsilon+\varepsilon \text { sij }} \quad \zeta \frac{\text { fo }(\zeta, x, t)}{\text { fo }(\varepsilon, x, t)} Q_{s i j}(\zeta) \mathrm{d} \zeta \\
& +\frac{-2 m}{M} \varepsilon^{2} Q_{m}\left(1-\frac{k T}{e} B(\varepsilon, x, t)\right) \\
& \frac{E}{3 N} \varepsilon e^{-V_{m t}} \frac{f_{1}(\varepsilon, x, 0)}{f_{0}(\varepsilon, x, t)}-\frac{1}{3 N} \int_{0}^{\varepsilon} \frac{\zeta e^{-V m t}}{f_{0}(\varepsilon, x, t)} \frac{\partial f_{1}(\zeta, x, 0)}{\partial x} d \zeta
\end{aligned}
$$


The analysis of this equation now proceeds by a sequence of approximations. The basic assumptions are:

i) $B$ is a weak function of $\varepsilon$,

ii) $B$ is invariant within a collision time and distance,

iii) $\mathrm{C}(\mathrm{x}, \mathrm{t})$ can be approximated as:

$$
c(x, t) \approx \int_{0}^{\infty} e^{-\frac{\left\langle\sqrt{3 Q_{m} Q_{i}}\right\rangle}{E(x, t) / N} \varepsilon}
$$

The approximation used for $\mathrm{C}(\mathrm{x}, \mathrm{t})$ is based on an energy averaged $\mathrm{B}(\varepsilon)$ found in an earlier analysis for uniform conditions in steady state, and for $\mathrm{m} / \mathrm{M}$ taken as zero.2,3,5 These assumptions lead to a sequence of manipulations:

a) $\int \mathrm{B} d \varepsilon$ is approximated as $\left(\mathrm{B}^{*} \varepsilon\right)$,

b) the term in equation (27) which contains time derivatives is expressed as two integrals in the form of incomplete gamma functions, and each in turn is approximated by a two point trapezoid rule,

c) the time integral term of equation (27) is simplified to:

$$
B * \int e^{-v_{m}}{ }^{*}(t-\tau) d \tau,
$$

as suggested by the conditions expressed as equations (26), also the limit of this integral at $t=0$ identically cancels the $f_{1}$ term in equation (27),

d) from (28): $\quad \partial \ln [C(x, t)] / \partial t=(3 / 2) \partial \ln [E(x, t) / N] / \partial t$, and similarly for $\partial / \partial \mathbf{x}$,

e) the inelastic collision integrals in equation (27) are approximated by $\varepsilon^{*} \mathrm{Q}_{\mathrm{i}} / \mathrm{B}(\varepsilon, \mathrm{x}, \mathrm{t})$, as was done in an earlier analysis. ${ }^{5}$ The resulting equation for $B(\varepsilon, x, t)$ is: 


$$
\begin{aligned}
& -\frac{\varepsilon}{2 v_{m}} \frac{\partial B}{\partial t}-\frac{1}{2 v_{m}} \frac{\partial}{\partial t} \ln (C)+\left(\frac{E}{N}\right)^{2} \frac{B}{3 \varepsilon Q_{m}^{2}} \\
& +-\frac{Q_{i}}{Q_{m}} \frac{1}{\varepsilon B}-\frac{2 m}{M}\left(1-\frac{k T}{e} B\right)
\end{aligned}
$$

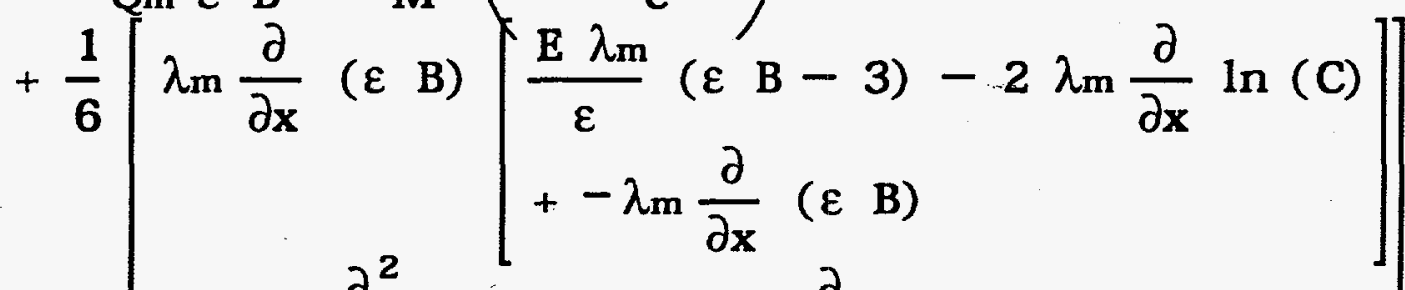

$$
\begin{aligned}
& +\lambda_{m^{2}} \frac{\partial^{2}}{\partial x^{2}}(\varepsilon \quad B)-B \lambda m \frac{\partial}{\partial x}\left(\lambda_{m} E\right) \\
& +\frac{E}{\varepsilon} \lambda m^{2}(\varepsilon B-2) \frac{\partial}{\partial x} \ln (C)+\lambda m^{2} \frac{\partial^{2}}{\partial x^{2}} \ln (C) \\
& +-\left(\lambda m \frac{\partial}{\partial x} \ln (C)\right)^{2} \\
& =\quad 0
\end{aligned}
$$

A quadratic equation for $\mathrm{B}(\varepsilon, \mathrm{x}, t)$ results from (29) given the two conditions shown as equations (26), and utilizing the definitions $\omega=\partial / \partial t \ln (C)$, and $1 / \lambda_{e}=1 / 6 \partial / \partial x \ln (C)$. The positive solution of this quadratic is given by equation (4), with terms as described by (5) through (18), but with this important exception: function $\Phi(\varepsilon, \mathbf{x}, \mathbf{t})$, which appears in equations (5), (6), and (7), is an ad hoc modification.

The addition of factor $\Phi(\varepsilon, x, t)$ is justified on the following grounds. The B of equation (4) becomes infinite when $(U+\mu \mathrm{kT} / \mathrm{e})$ equals zero, and then $f$ becomes infinitely steep. This occurs when $\varepsilon$ equals $\varepsilon_{\mathrm{m}}$ which is defined in (7). Electrons in the neighborhood of $(x, t)$ with energy higher than $\varepsilon_{m}(\varepsilon, x, t)$ simply do not sense the electric field, they gain less energy from the field between collisions than they do by purely thermal effects. As a result electrons above $\varepsilon_{m}(\varepsilon, x, t)$ are distributed in what would be a Maxwellian at the gas temperature (kT/e in $\mathrm{eV})$ if $\mathrm{Q}_{i}$ were absent. The factor $\Phi$ effects this transition. Note that for a uniform field $1 / \lambda_{e}=0, \varepsilon_{m}=\infty, \Phi=1$. 


\section{Model Gas}

Examples are shown for a model gas with molecular weight $\mathrm{Z}=29$ (like air), a constant $\mathrm{Q}_{\mathrm{m}}=10^{-15} \mathrm{~cm}^{2}$, at temperature $\mathrm{T}=300^{\circ} \mathrm{K}$, and at number density $\mathrm{N}=3.54 \times 10^{16} \mathrm{~cm}^{-3}$ (1 Torr). An inelastic cross section similar to vibrational excitation in $\mathrm{N}_{2}$ and with a peak of $\mathrm{Q}_{\mathrm{i}}(1.7 \mathrm{eV})=3 \times 10^{-16} \mathrm{~cm}^{2}$ was chosen and is shown below.

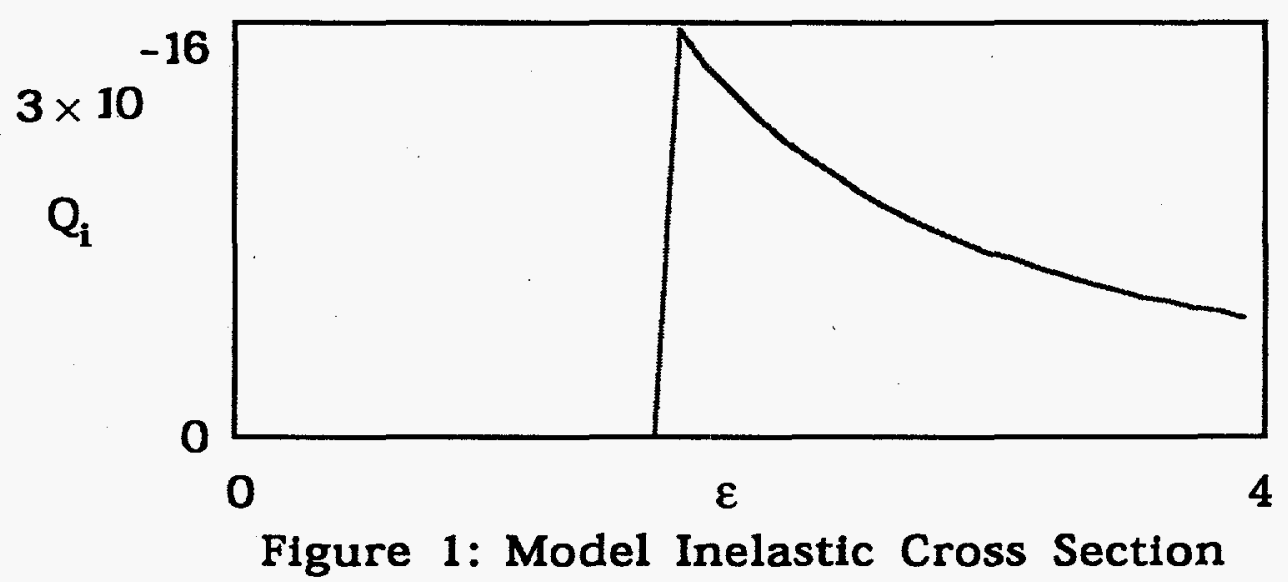

\section{Examples of Time Variation}

The first three examples are linear $\mathrm{E} / \mathrm{N}$ ramps up to 100 Townsends $\left(1 \mathrm{Td}=10^{-17}\right.$ Volts- $\left.\mathrm{cm}^{2}\right)$, particulars are noted by each figure (Figures 2 through 5). The next three examples are for linear field collapse from an initially steady 100 Td (Figures 6 through 12). Then follow two examples for $\mathrm{E} / \mathrm{N}$ a sine wave with phase angle $\phi$ after $\mathrm{t}=0$. E/N prior to $\mathrm{t}=0$ is steady at $100 \sin (\phi) \mathrm{Td}$. These examples have $\phi=\pi / 4$, and are displayed as Figures 13 through 17 . All these examples are uniform in space. 


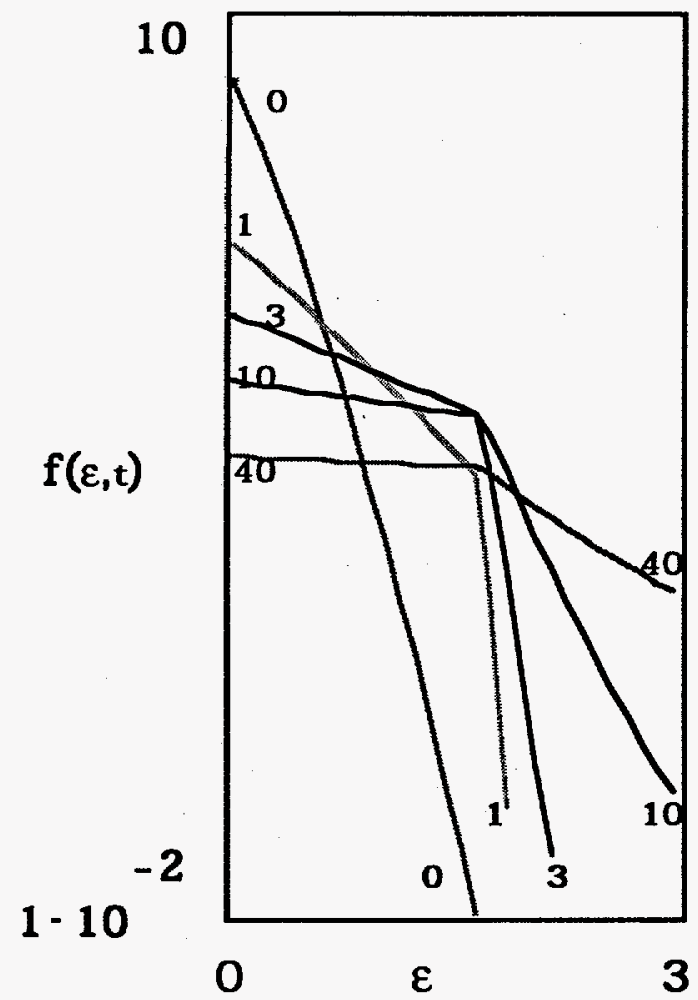

$\operatorname{LOG}[f(\varepsilon, t)]$ vs. $\varepsilon(e V)$.

$\mathrm{E} / \mathrm{N}=0$ to $100 \mathrm{Td}$

in $20 \mu s$,

labeled by time step,

$\Delta \mathrm{t}=0.625 \mu \mathrm{s}$,

210 collisons $/ \Delta t$,

$\omega / v<.009$

Figure 2: $100 \mathrm{Td}, 20 \mu \mathrm{s}$ ramp

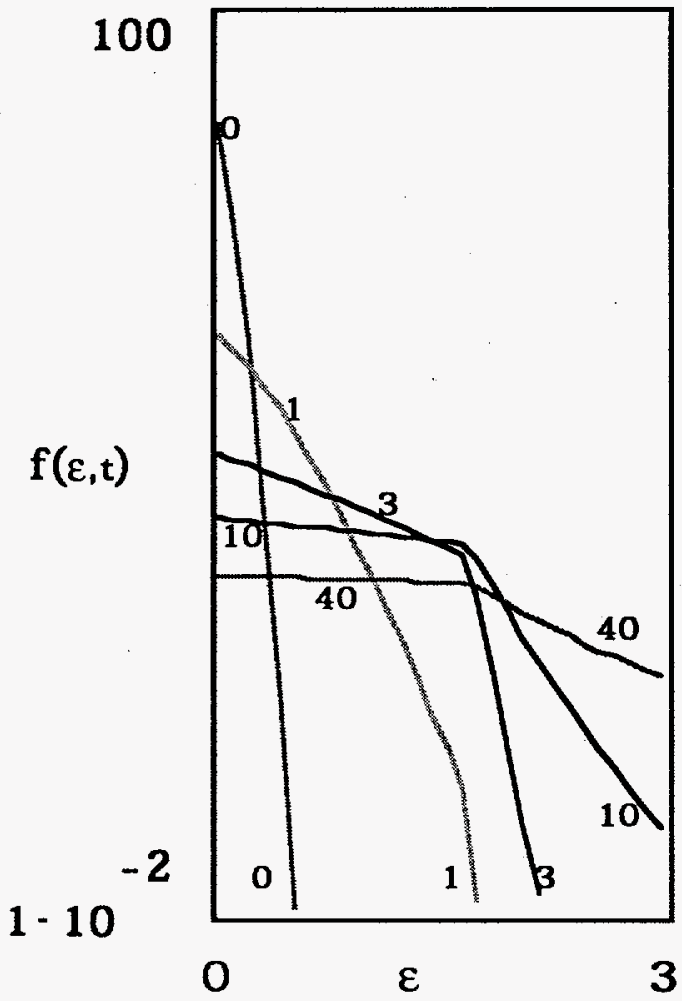

$\operatorname{LOG}[f(\varepsilon, \mathrm{t})]$ vs. $\varepsilon(e \mathrm{v})$,

$\mathrm{E} / \mathrm{N}=0$ to $100 \mathrm{Td}$ in $2 \mu \mathrm{s}$,

labeled by time step. $\Delta \mathrm{t}=62.5 \mathrm{~ns}$,

21 collisions $/ \Delta t$, $\omega / v<.09$

Figure 3: $100 \mathrm{Td}, 2 \mu \mathrm{s}$ ramp 


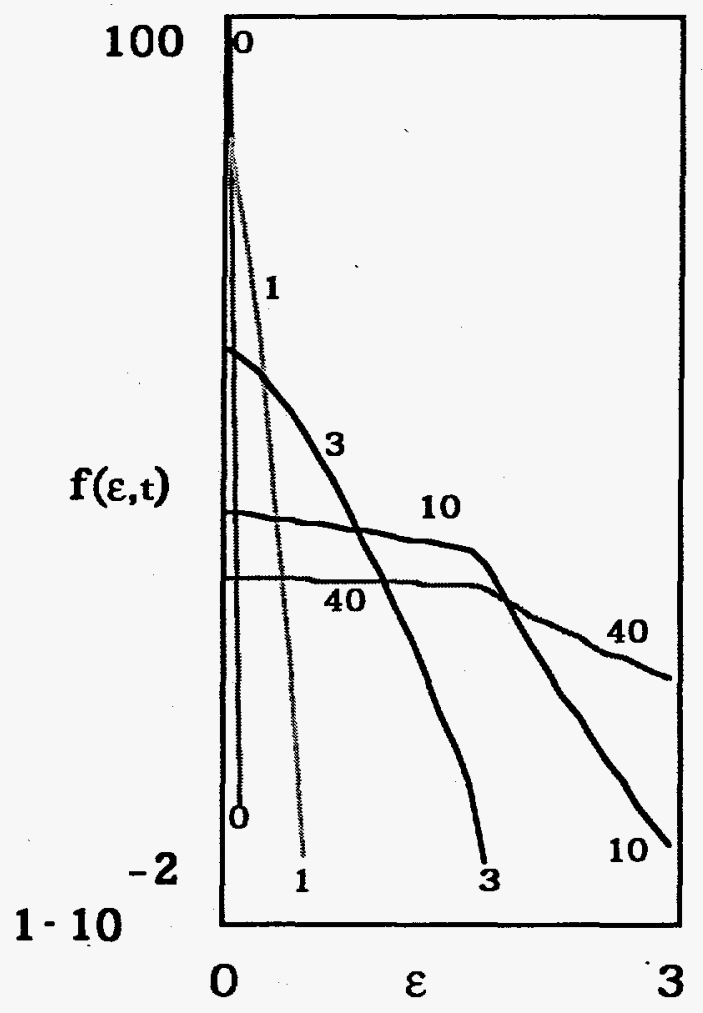

$\operatorname{LOG}[f(\varepsilon, t)]$ vs. $\varepsilon(e V)$,

$\mathrm{E} / \mathrm{N}=0$ to $100 \mathrm{Td}$ in $0.2 \mu \mathrm{s}$, labeled by time step, $\Delta \mathrm{t}=6.25 \mathrm{~ns}$, 2 collisions $/ \Delta t$, $\omega / v<0.9$

Figure 4: $100 \mathrm{Td}, 0.2 \mu \mathrm{s}$ ramp

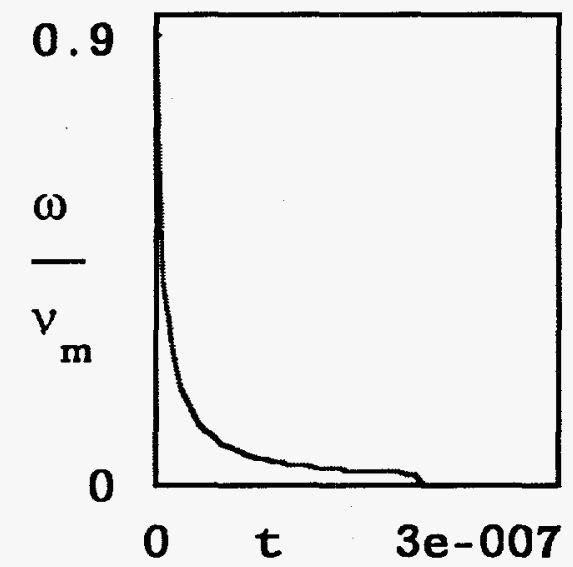

Figure 5: $\omega / v_{m}$ for example of Figure 4 


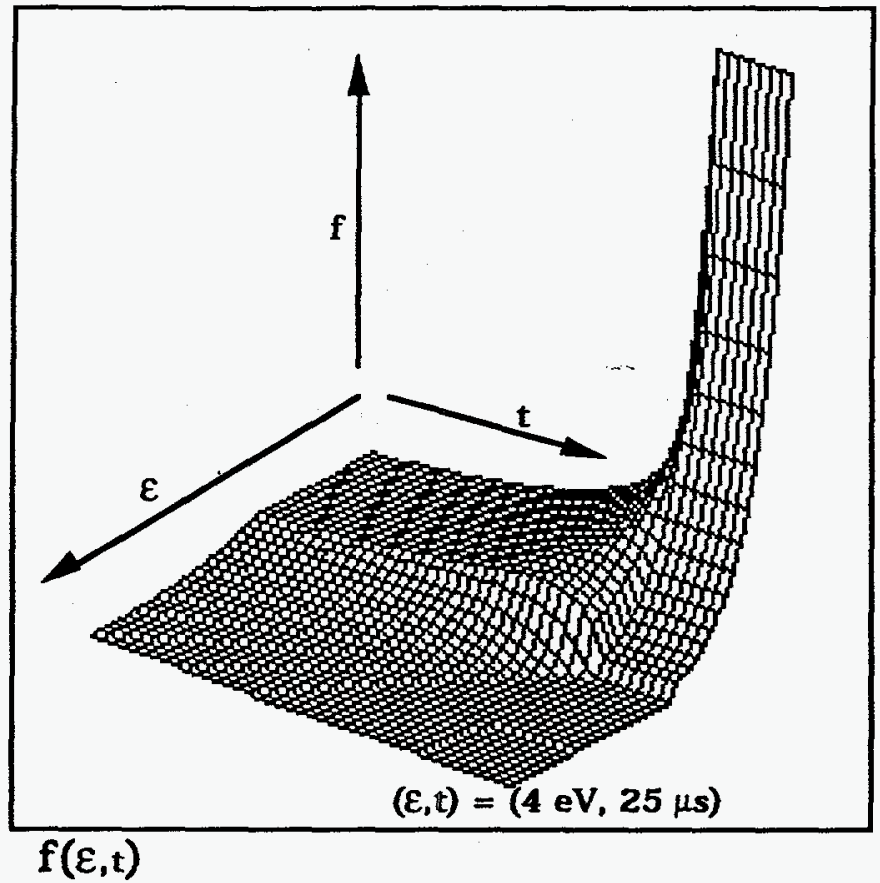

Figure 6: Field Collapse from $100 \mathrm{Td}$ in $20 \mu \mathrm{s}$

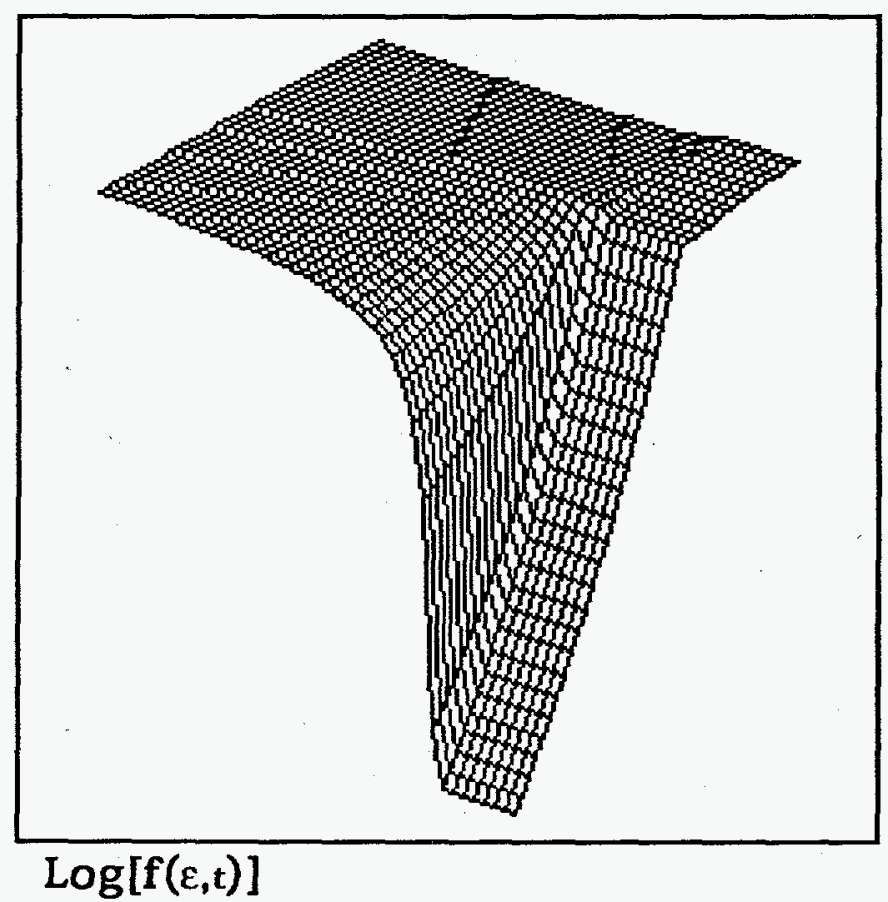

Figure 7: Log representation of Figure 6 


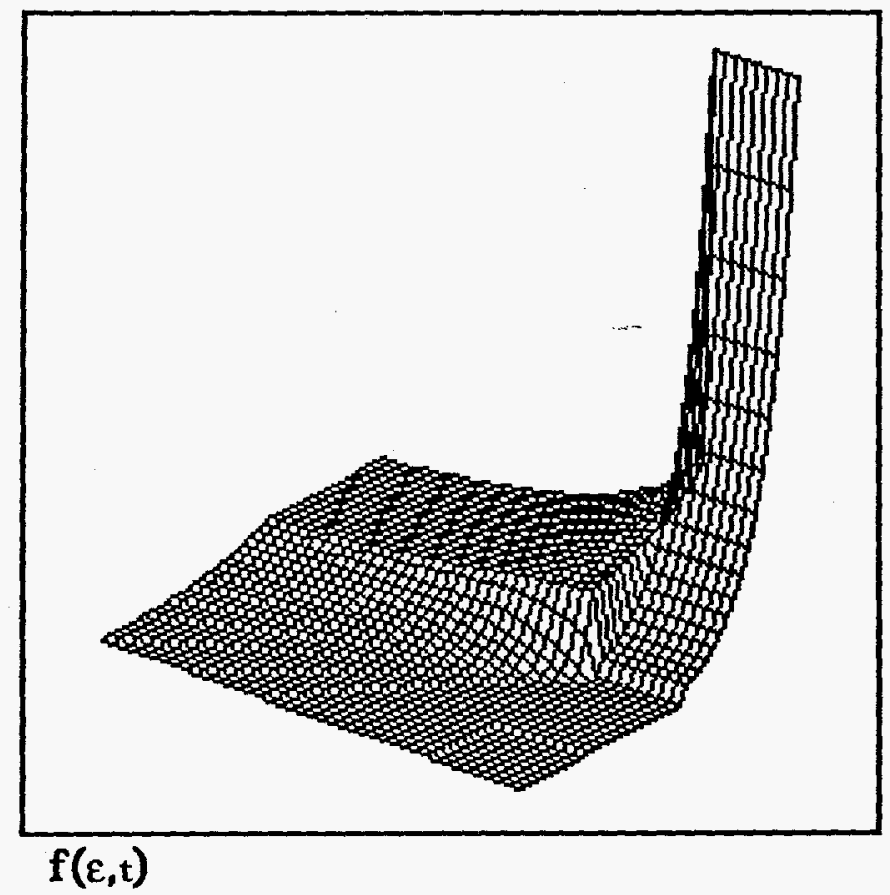

Figure 8: Field Collapse from $100 \mathrm{Td}$ in $2 \mu \mathrm{s}$ $(\varepsilon, t)$ from $(0,0)$ to $(4 \mathrm{eV}, 2.5 \mu \mathrm{s})$,

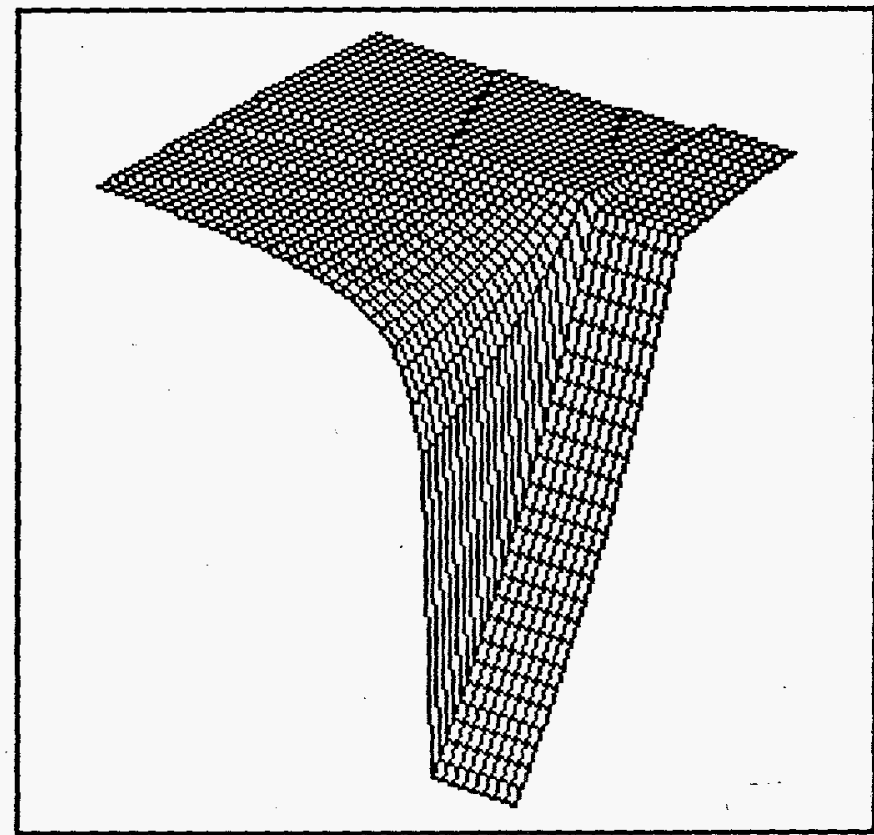

$\log [f(\varepsilon, t)]$

Figure 9: Log representation of Figure 8 


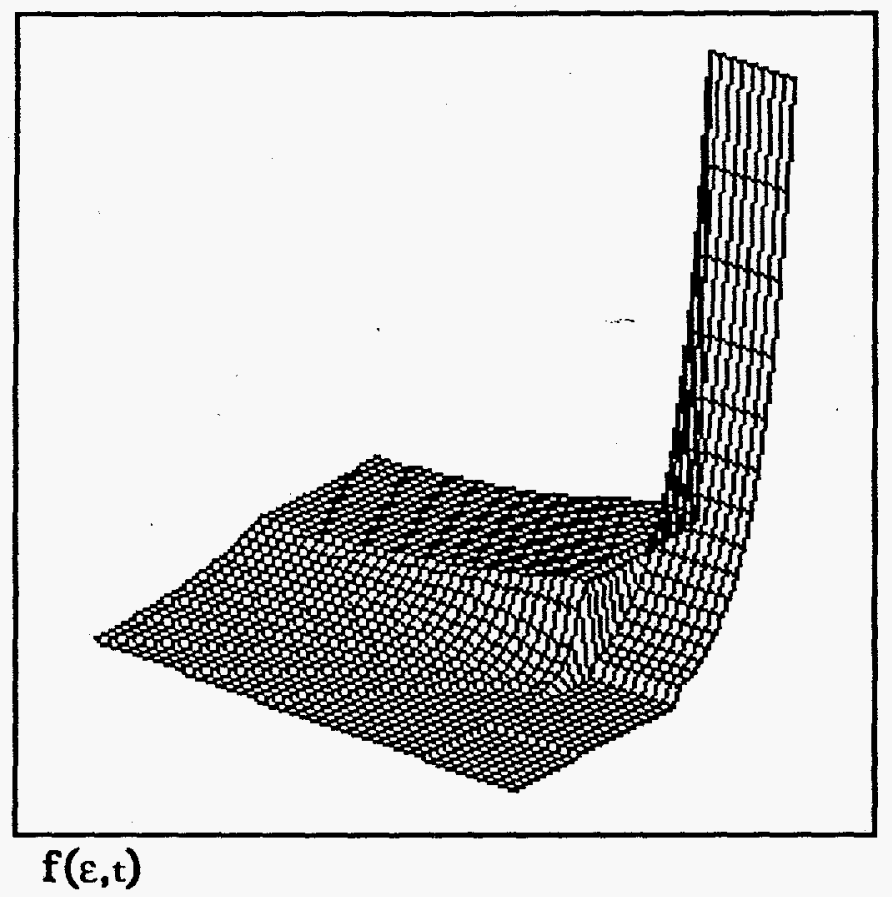

Figure 10: Field Collapse from $100 \mathrm{Td}$ in $0.2 \mu \mathrm{s}$ $(\varepsilon, t)$ from $(0,0)$ to $(4 \mathrm{eV}, 0.25 \mu \mathrm{s})$

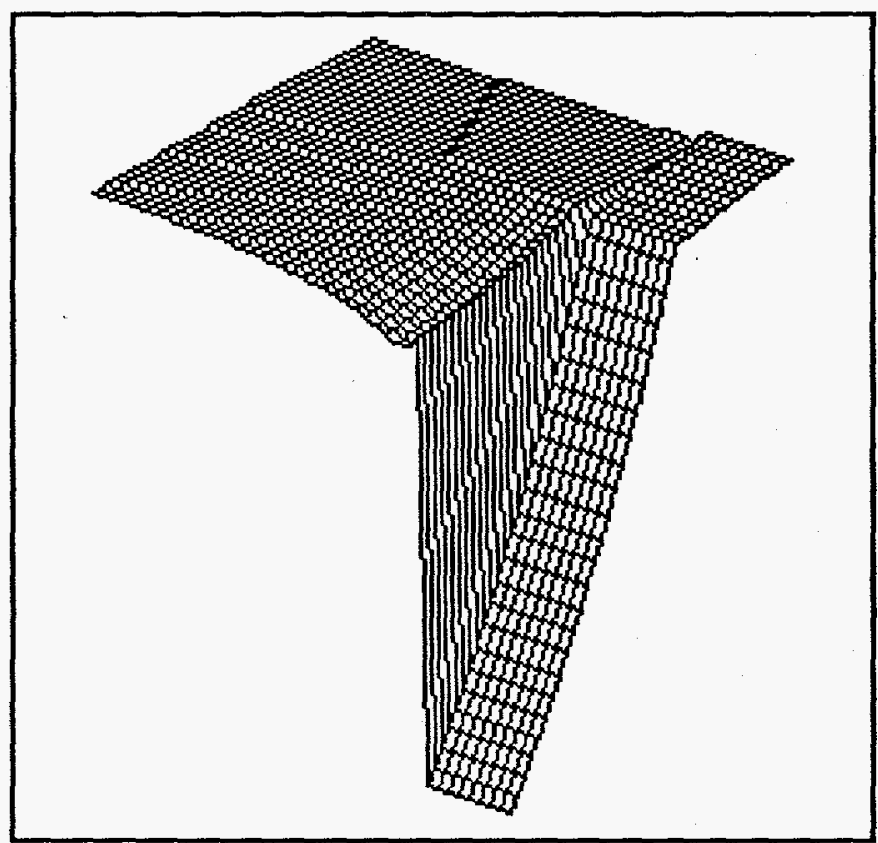

$\log [f(\varepsilon, t)]$

Figure 11: Log representation of Figure 10 


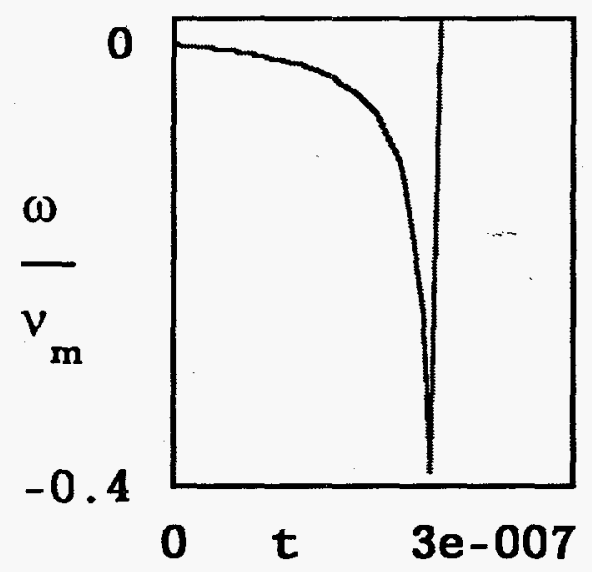

Figure 12: $\omega / v_{\mathrm{m}}$ for example of Figure 10

The collision frequency referred to, both as $v$ and $v_{m}$, in Figs. 2, 3, 4, 5,12 , and 17 , is the electron-molecule elastic collision frequency at $\mathrm{kT} / \mathrm{e}$. 


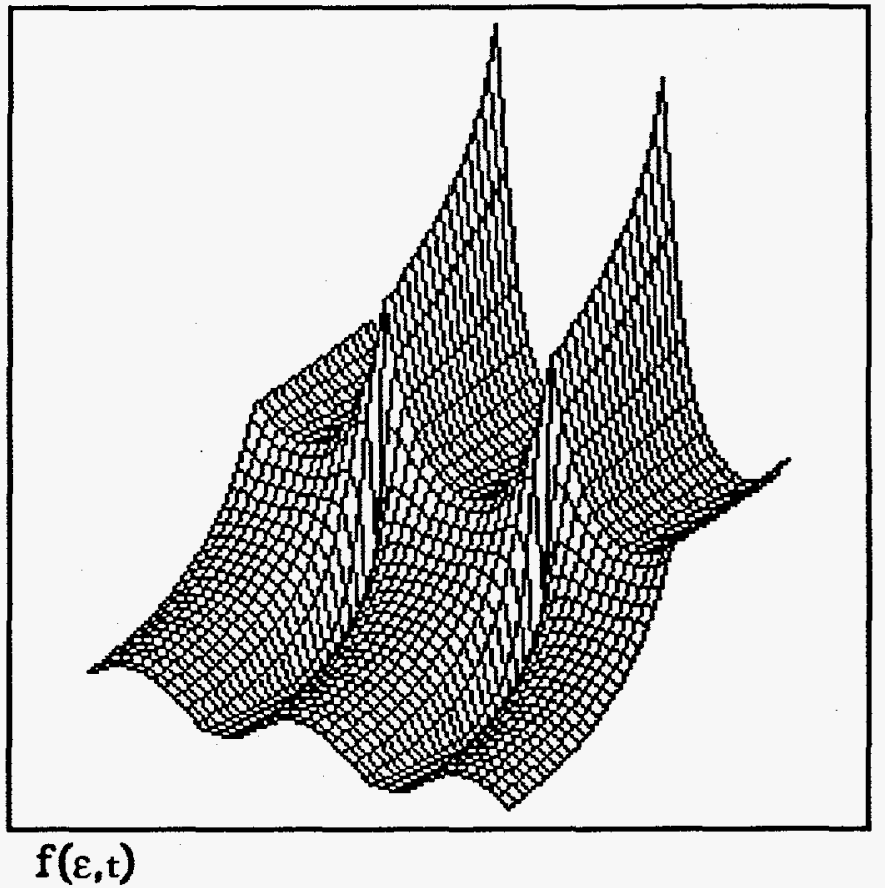

Figure 13: $100 \mathrm{Td}, 50 \mathrm{kHz}$ sine wave to $(\varepsilon, t)=(4 \mathrm{eV}, 25 \mu \mathrm{s})$

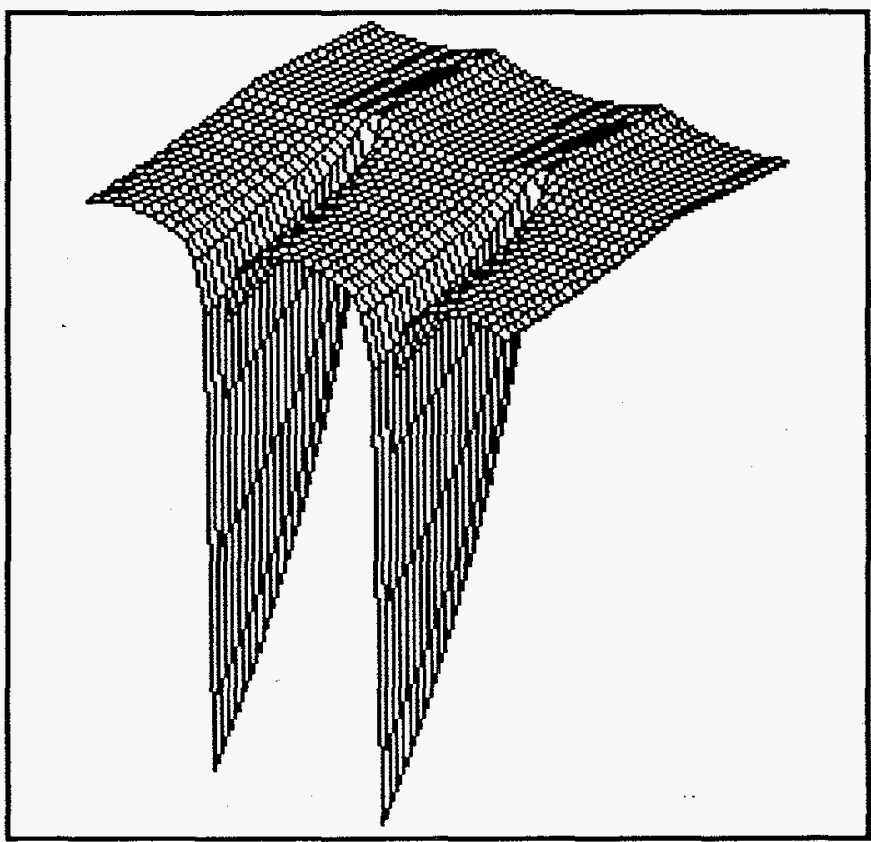

$\log [f(\varepsilon, t)]$

Figure 14: Log representation of Figure 13 


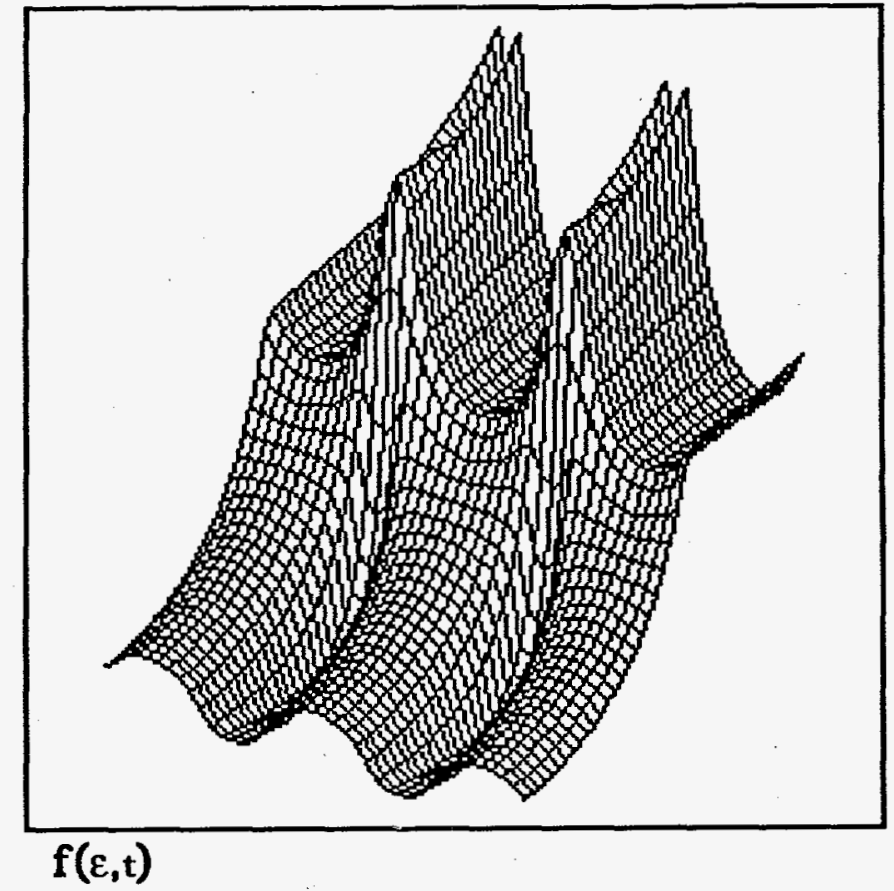

Figure 15: $100 \mathrm{Td}, 500 \mathrm{kHz}$ sine to $(\varepsilon, \mathrm{t})=(4 \mathrm{eV}, 2.5 \mu \mathrm{s})$

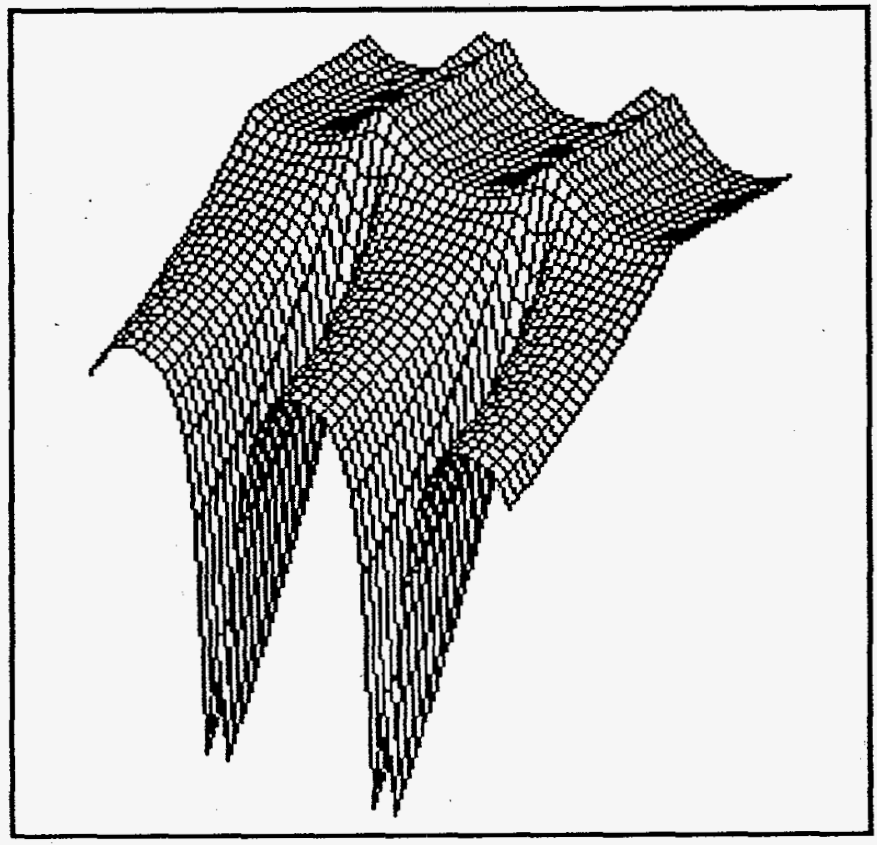

$\log [\mathbf{f}(\varepsilon, t)]$

Figure 16: Log representation of Figure 15 


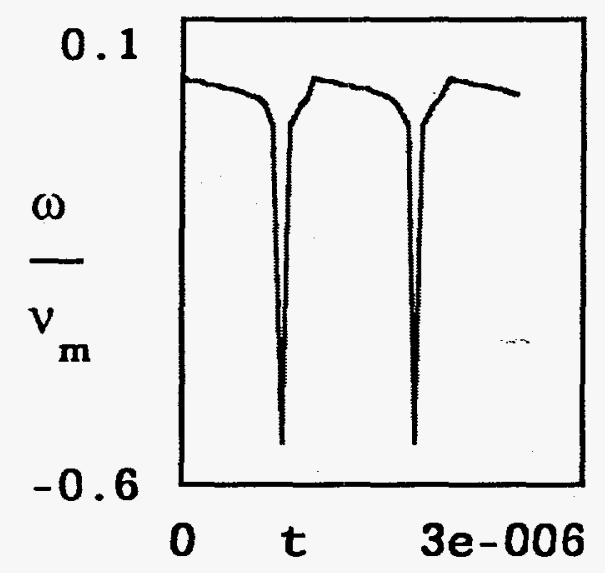

Figure 17: $\omega / v_{m}$ for example of Figure 15

\section{Examples of Spatial Variation}

The following examples have electric fields that decay exponentially with scaled distance $x / \lambda_{E}$, where coordinate $x$ and parameter $\lambda_{\mathrm{E}}$ are expressed in $\mathrm{cm}$. These examples have $\lambda_{\mathrm{E}}$ equal to 0.0282 and $0.282 \mathrm{~cm}$ respectively. The electron-molecule mean-freepath, $\lambda_{m}$, is $0.0282 \mathrm{~cm}$. Both examples display results for a total distance of $3 \lambda_{\mathrm{E}}$.

The first example has $\lambda_{\mathrm{E}}=\lambda_{\mathrm{m}}$ and exhibits a strong gradient effect, which is negligible in the second case. For each case the results are calculated twice: with $\mathrm{E}(\mathrm{x}, \mathrm{t})$ and its gradients, and then again for $E(x, t)$ but with its spatial and temporal derivatives, equations (9) and (1 1), set to zero: The "zero gradient" results are labeled by a letter $\mathrm{z}$ in their names. Figures 18 through 21 show the first example, Figures 22 and 23 are for the second. These examples are in steady state. 


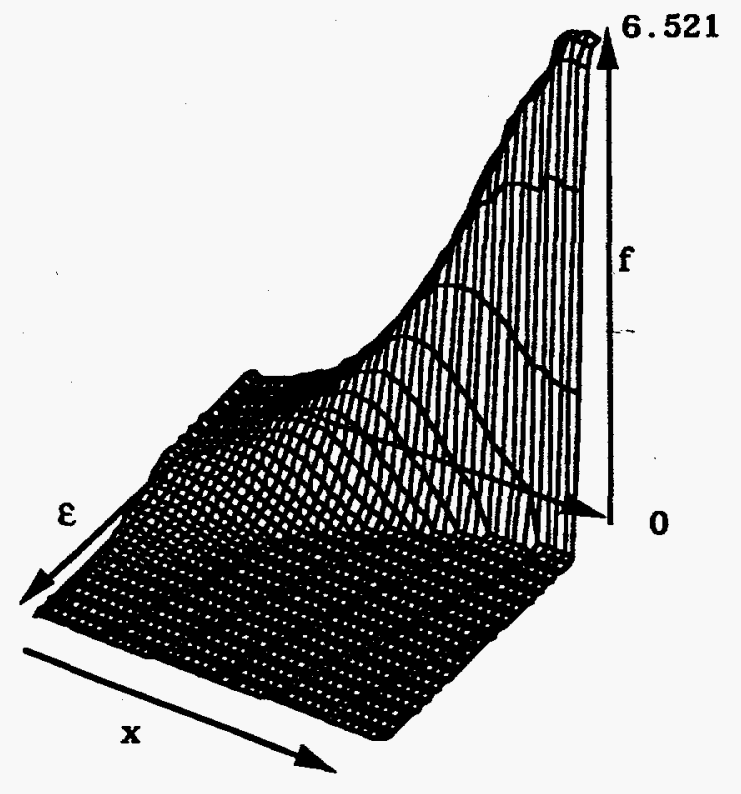

$f(\varepsilon, x)$

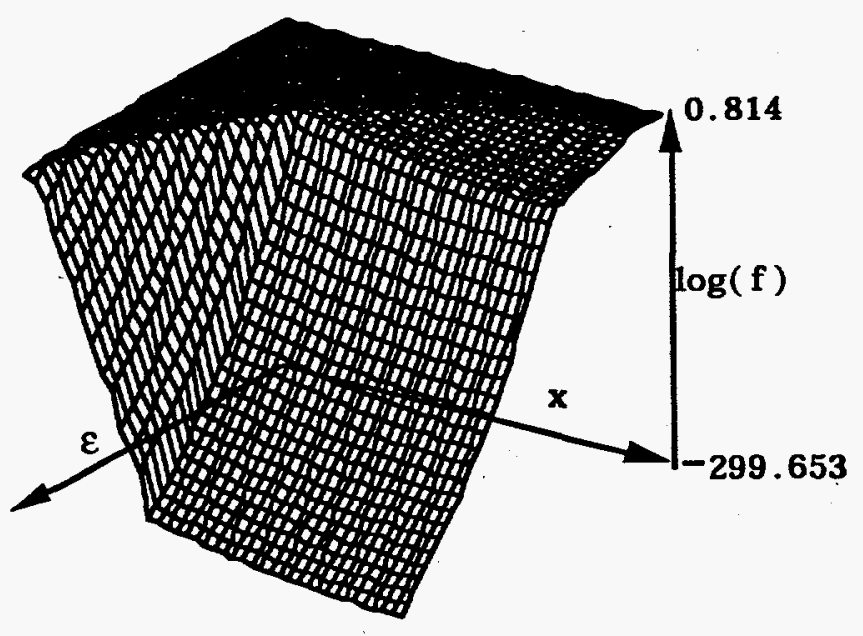

$\log (\mathbf{f})$

Figure 18: $f(\varepsilon, x)$ to $(\varepsilon, x)=(4 \mathrm{eV}, 0.0846 \mathrm{~cm}),. \lambda_{E}=0.0282$ 

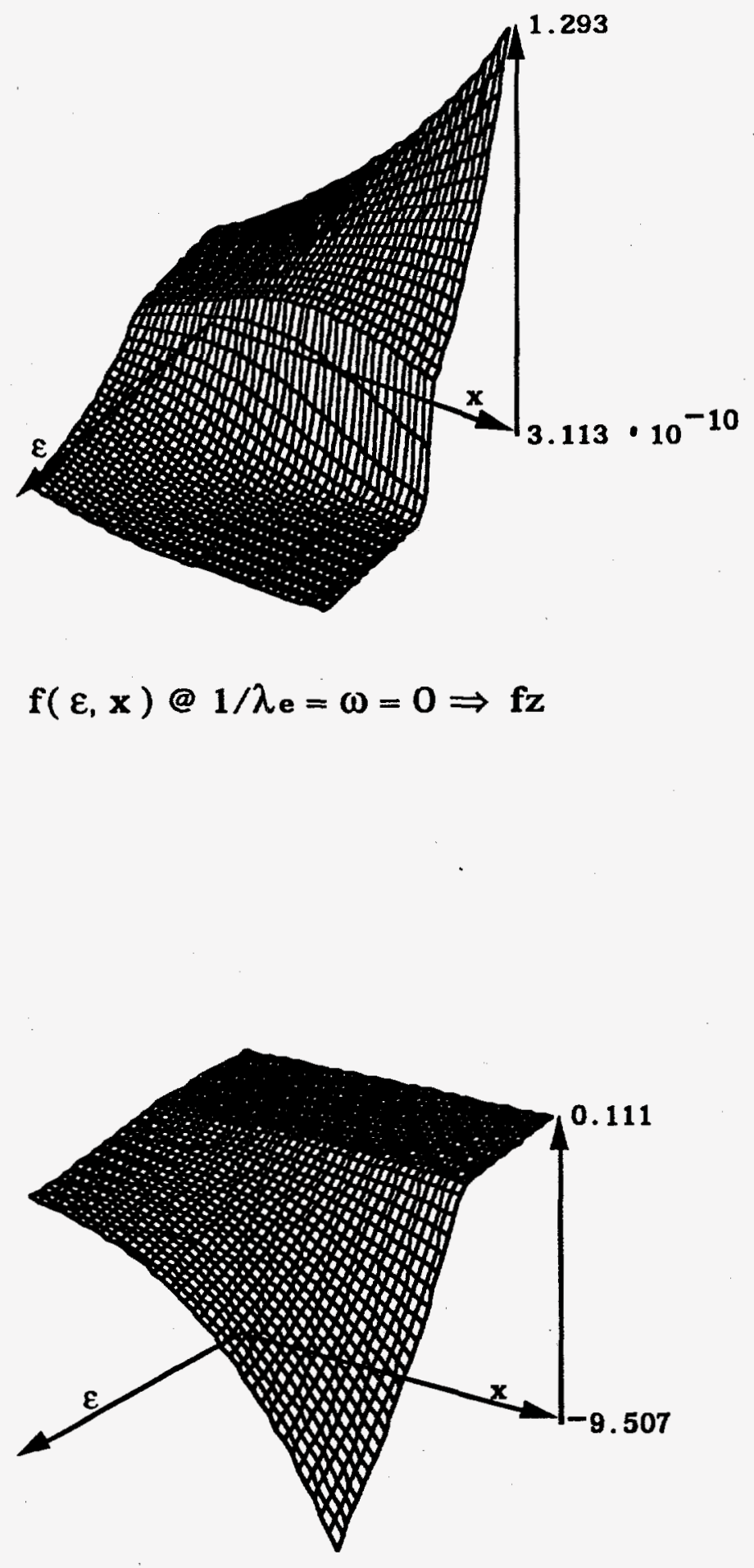

$\log (\mathrm{fz})$

Figure 19: $\mathrm{fz}(\varepsilon, \mathrm{x})$ to $(\varepsilon, \mathrm{x})=(4 \mathrm{eV}, 0.0846 \mathrm{~cm}),. \lambda_{\mathrm{E}}=0.0282$ 


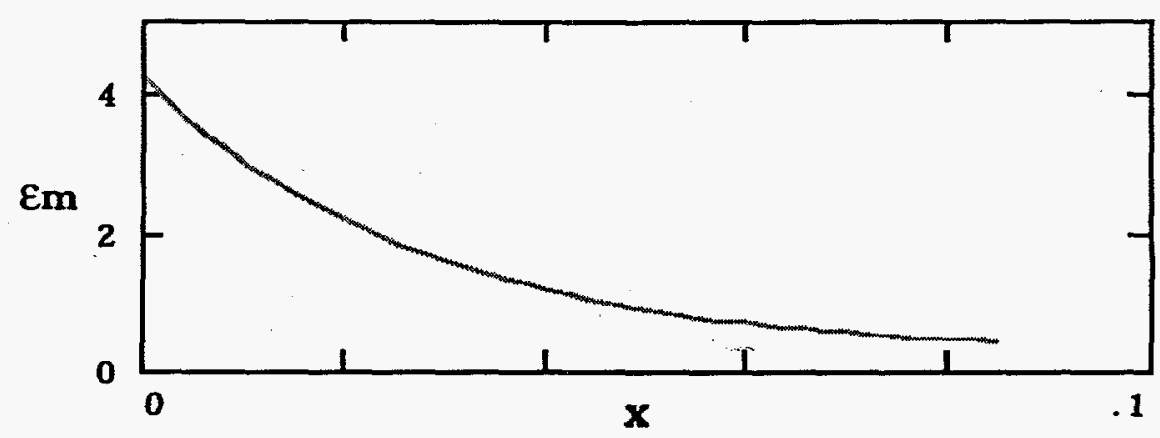

Figure 20: $\varepsilon_{m}(x)$, maximum energy sensing $E(x), \lambda_{E}=0.0282$
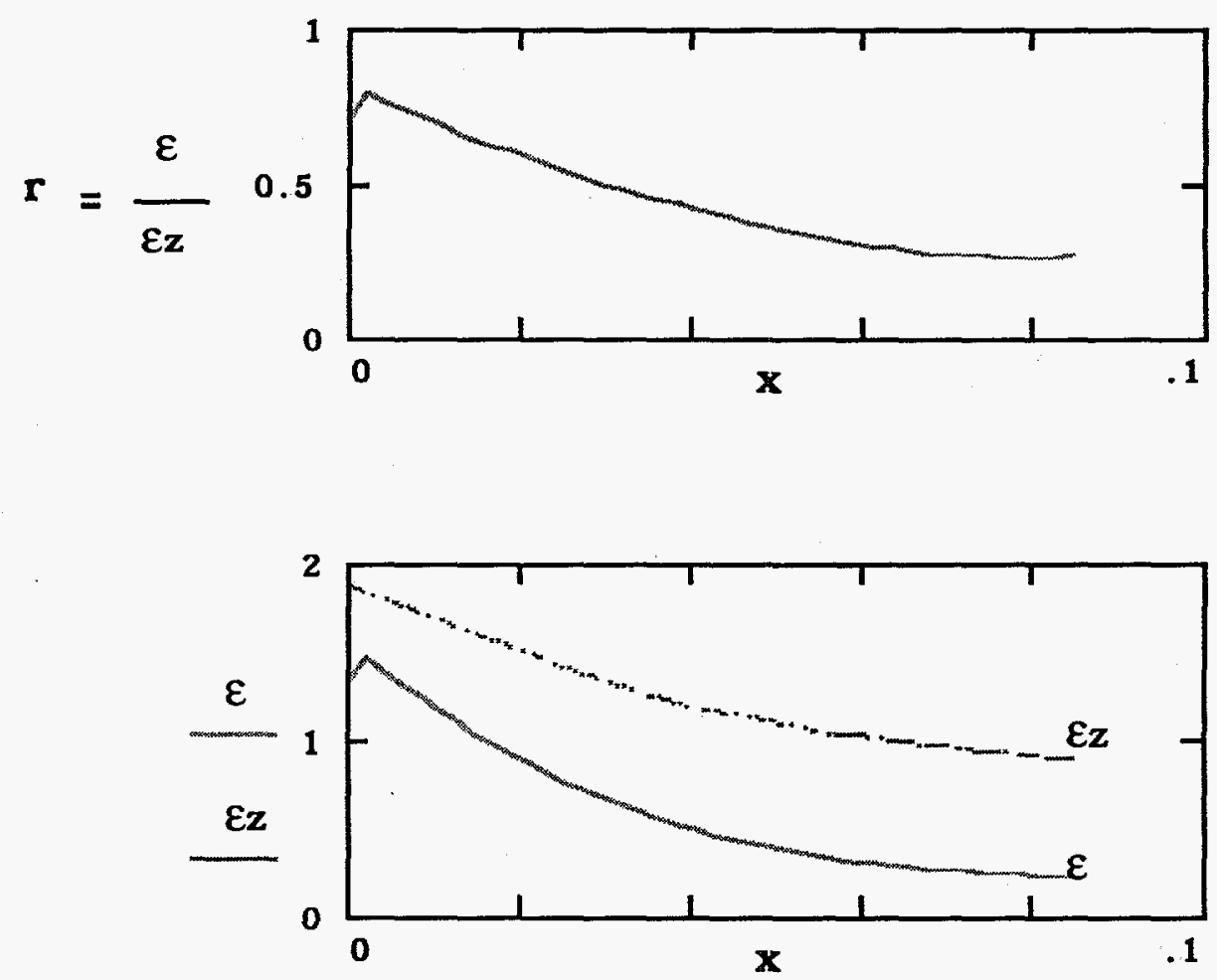

Figure 21: Comparison of $\varepsilon$ and $\varepsilon z$ shows the field gradient effect, $\lambda_{E}=0.0282$ 
If the previous example is recalculated with $\lambda_{E}=0.282 \mathrm{~cm}$, or ten times larger than the previous scale length and mean free path, then $f(\varepsilon, x)=f z(\varepsilon, x)$, and it appears very similar to Figure 19 though on the longer length scale. Here the gradient effect is negligible, as is evident from Figures 22 and 23.

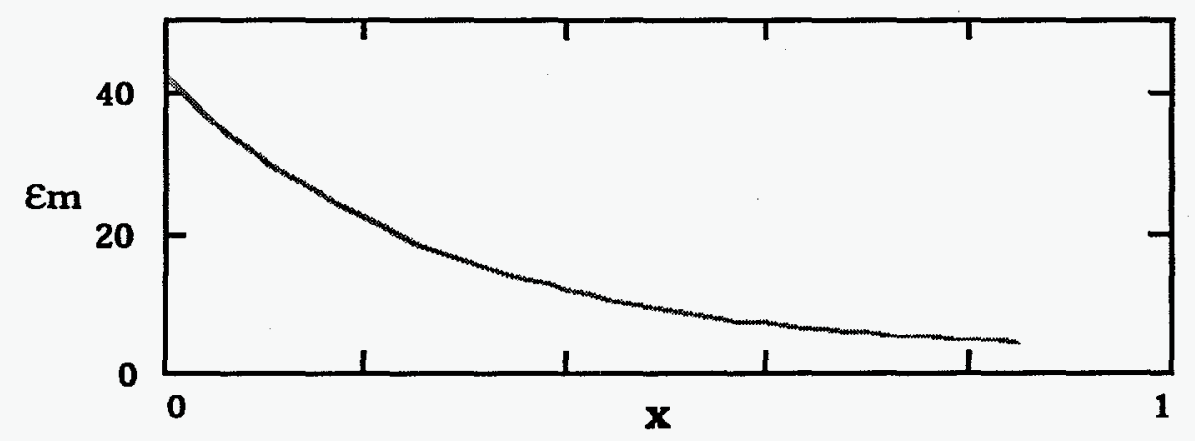

Figure 22: $\varepsilon_{\mathrm{m}}(\mathrm{x})$, maximum energy sensing $\mathrm{E}(\mathrm{x}), \lambda_{\mathrm{E}}=0.282$
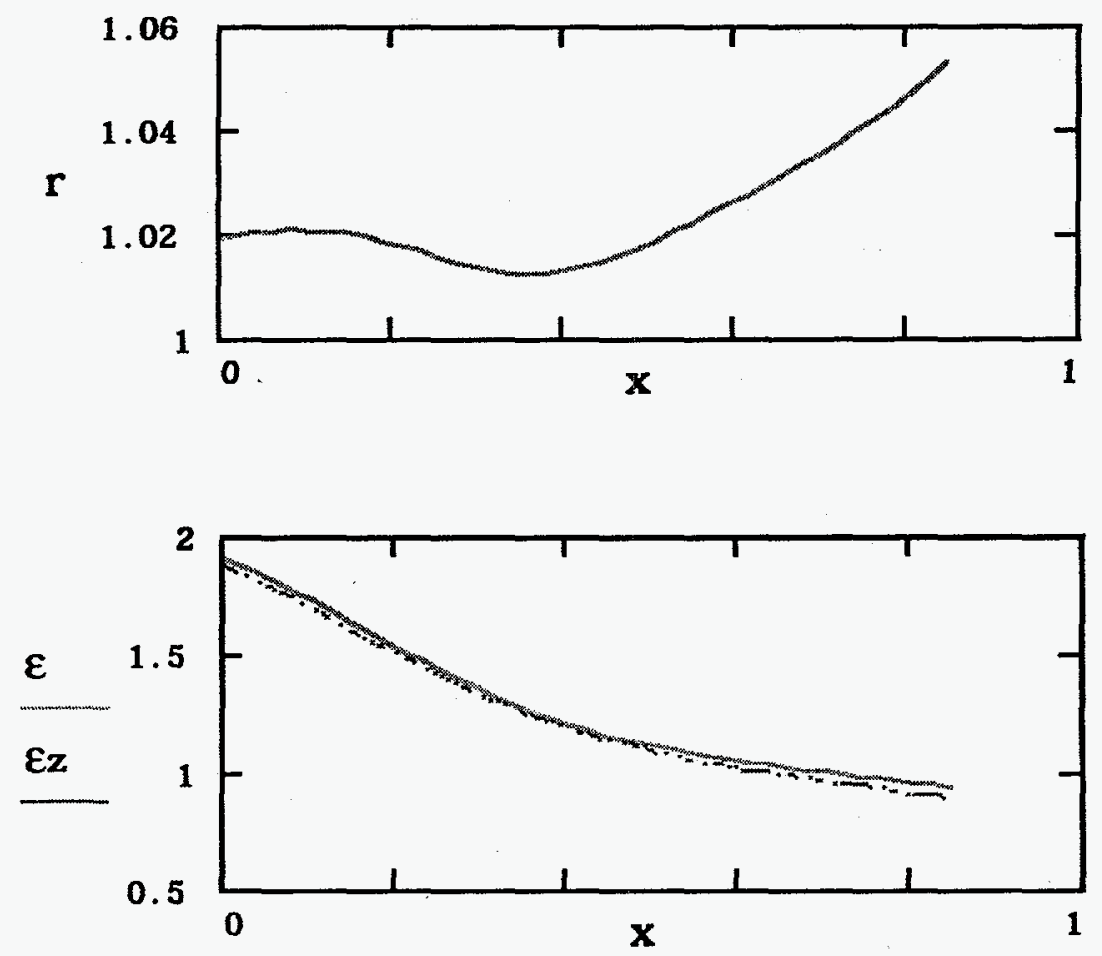

Figure 23: Negligible field gradient effect, $\lambda_{E}=0.282$ 
Example of Variation in Space and Time

The last example is for $\mathrm{E} / \mathrm{N}$ a $500 \mathrm{kHz}, 100 \mathrm{Td}$ sine with $\phi=\pi / 4$, and an exponential decay along $x / \lambda_{E}$ for $\lambda_{E}=0.0282$.

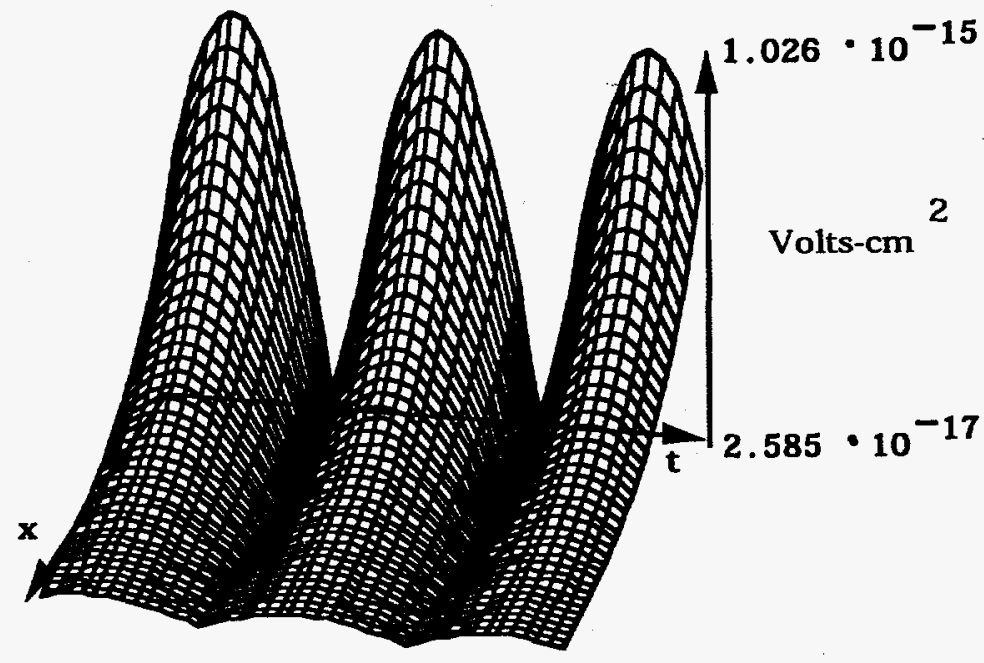

$E / N(x, t)$

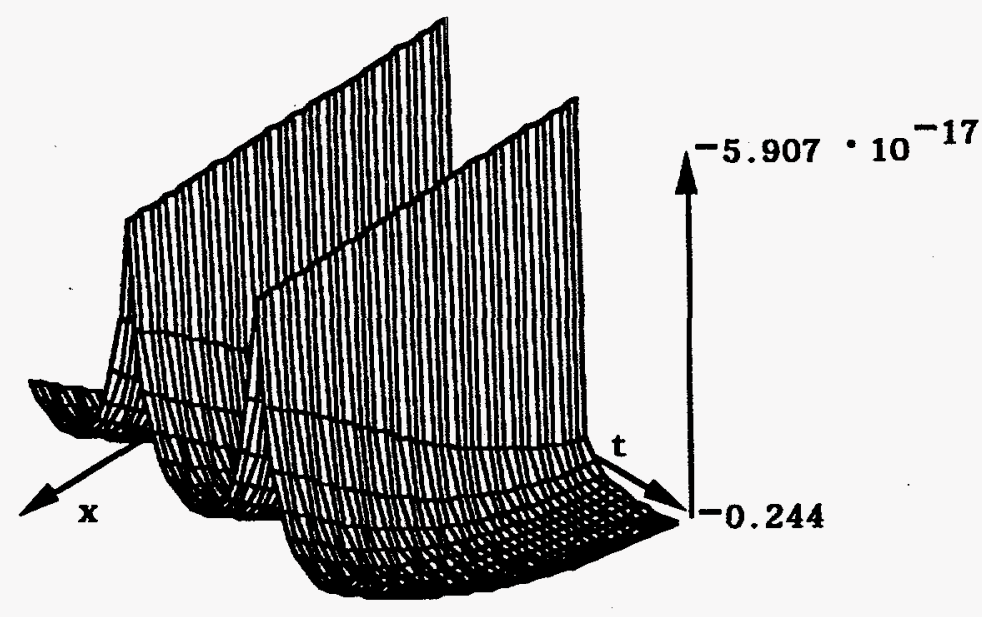

$$
\lambda_{\mathrm{m}}(\mathrm{kT} / \mathrm{e}) / \lambda_{\mathrm{e}}(\mathrm{x}, \mathrm{t})
$$

Figure 24a: $\mathrm{E} / \mathrm{N}$ and the functions dependent on it. 


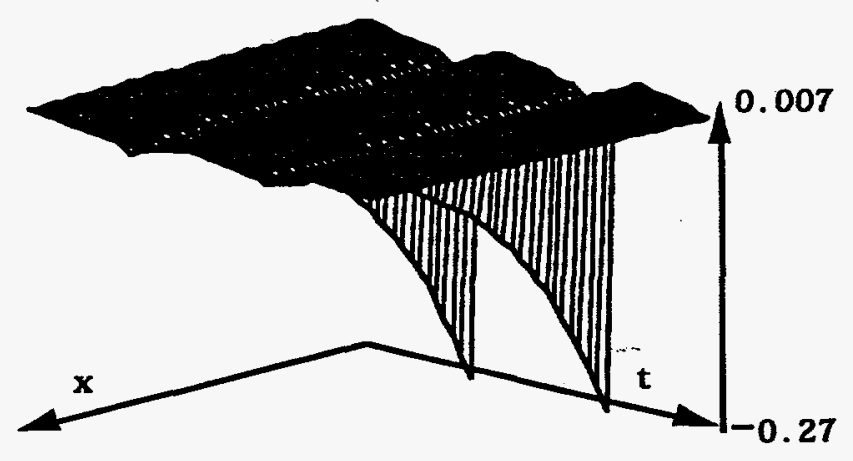

$\omega(x, t) / 2 \operatorname{Vm}(k T / e)$

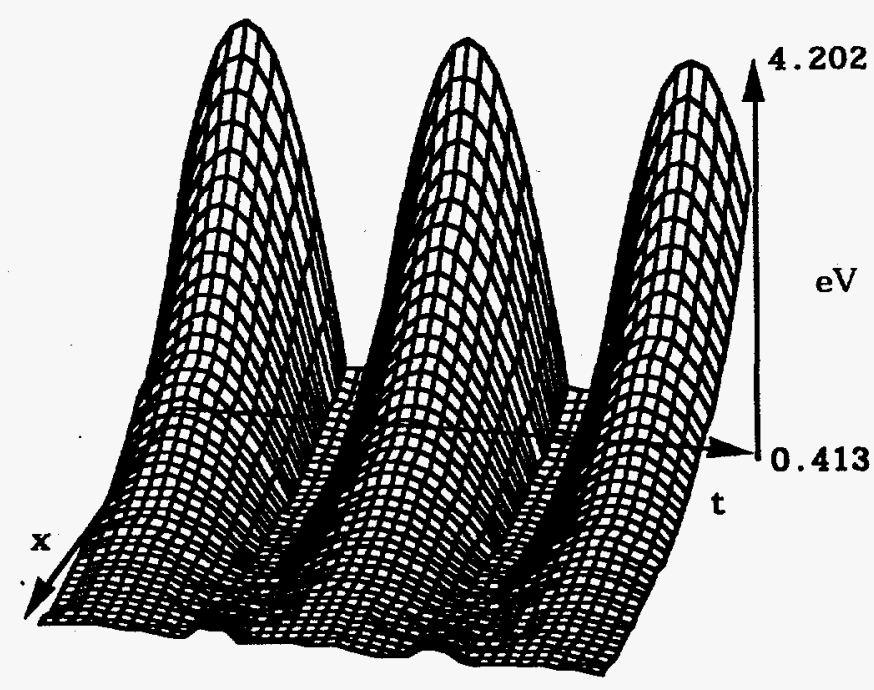

\section{$A\left(\right.$ djusted) $\varepsilon_{m}(x, t)$}

Figure 24b: E/N and the functions dependent on it. ( $A \varepsilon_{m}$ is $\varepsilon_{m}$ adjusted by removing large values at node lines of temporal sine) 

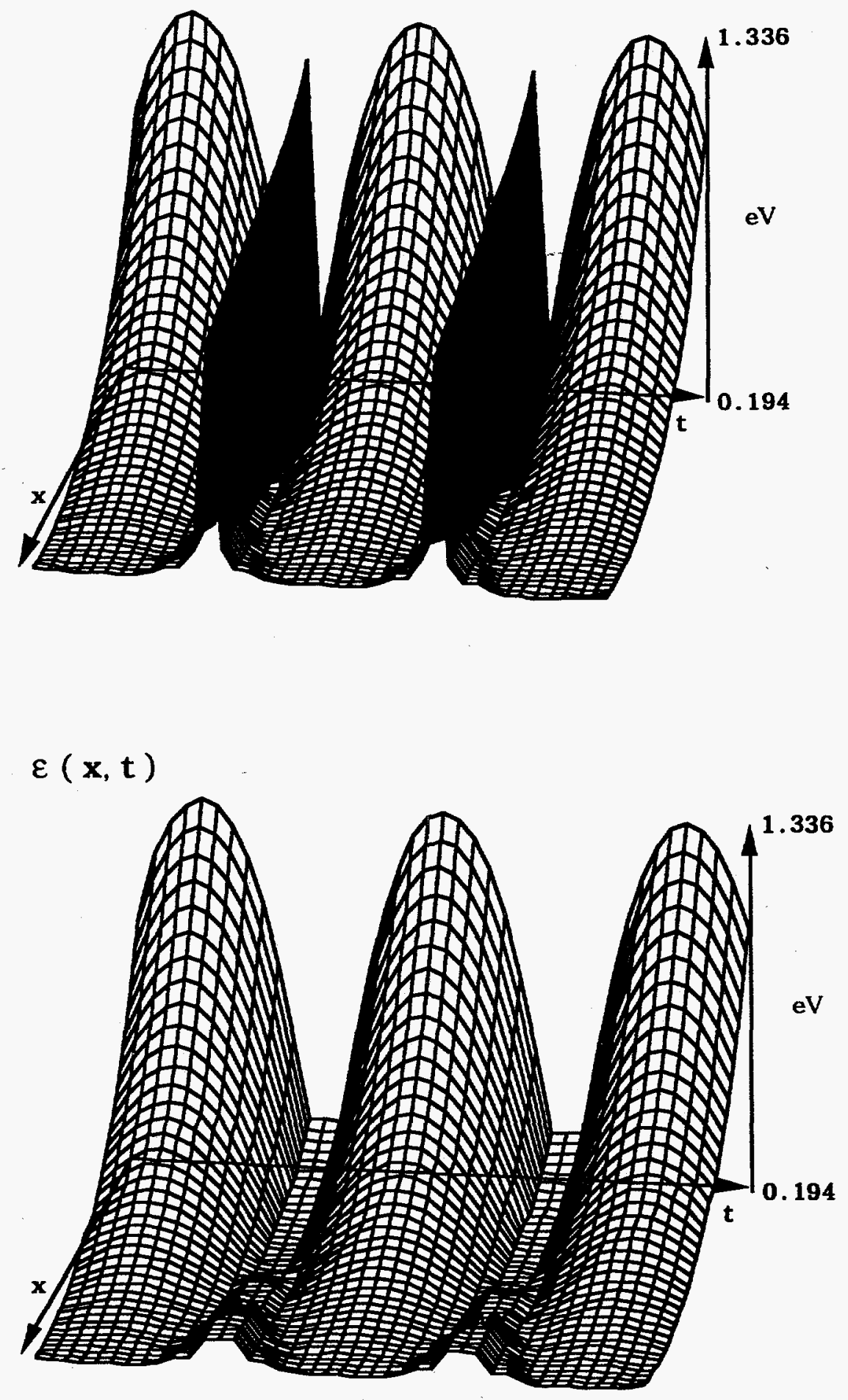

$A \varepsilon(x, t)$, (adjustment along node lines)

Figure 25: $\varepsilon(\mathrm{x}, \mathrm{t})$ to $(\mathrm{x}, \mathrm{t})=(0.0846 \mathrm{~cm} ., 2.5 \mu \mathrm{s})$ 

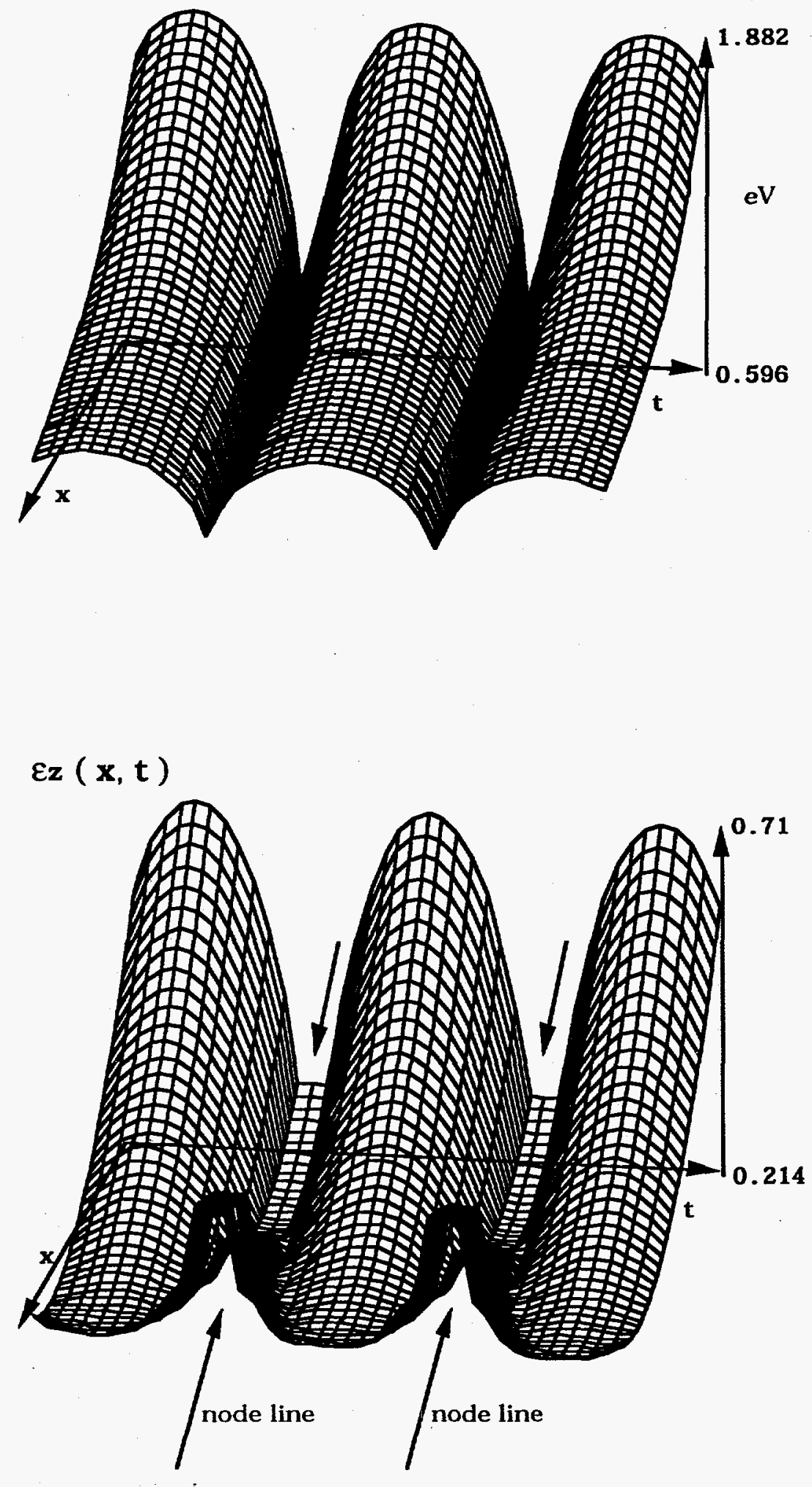

Ratio $\varepsilon / \varepsilon_{\mathbf{z}}(\mathbf{x}, \mathbf{t})$, using $\varepsilon$ adjusted along the node lines Figure 26: $\varepsilon z$ and $\varepsilon / \varepsilon z$ to $(x, t)=(0.0846 \mathrm{~cm}, 2.5 \mu \mathrm{s})$ 
The large excursions that occur in $\varepsilon$ and other functions for large $\omega / 2 v_{m}$ at low $\mathrm{E} / \mathrm{N}$ (as in the sine nodes) arise from the basic discrepancy between the actual form of $B(\varepsilon, x, t)$ and the very approximate form for $B$ utilized within the normalization integral, equation (28), during the derivation of equation (4). Basically, the approximations used between equations (27) and (29) are not sufficiently accurate for $\mathrm{E} / \mathrm{N}$ comparable to $\mathrm{Q}_{\mathrm{m}} \times \mathrm{kT} / \mathrm{e}$. In physical terms, the time dependent model breaks down when the energy gained per mean free path from the field becomes comparable to thermal energy.

\section{Conclusion}

This analytical model of inelastic electron kinetics with space and time dependent external electric fields is centered on $B(\varepsilon, x, t)$ as defined in equation (4). The model distribution function collapses to appropriate limiting behavior for uniform-static electric fields. In addition, the model distribution function along with its velocity and energy moments compare very favorably with calculated and measured properties of real gases in the uniform-static limit, as demonstrated in Ref. (5).

This model is convenient in that B is an explicit analytical form in which the influence of the field magnitude along with its spatial and temporal gradients at $(x, t)$ are individually accounted for in separate parameters. As few assumptions were made about the nature of $E(x, t)$ and the cross sections, a wide variety of electrically. excited gases can be modeled. The examples here clearly show how a time, or space, dependent solution can be quite different from a sequence of static, or uniform, solutions each at the local, instantaneous $\mathrm{E}(\mathrm{x}, \mathrm{t}) / \mathrm{N}$.

\section{Auspices}

This work was performed under the auspices of the U.S. DOE by LLNL under contract no. W-7405-Eng-48. 


\section{References}

1) B. E. Cherrington, Gaseous Electronics and Gas Lasers, Pergammon Press, 1979.

2) G. K. Bienkowski, "A Scaling Law for Energy Transfer by Inelastic Electron-Molecule Collisions in Mixtures," Proceedings of the Princeton University Conference on Partially Ionized Plasmas, in the $3^{\text {rd }}$ Symposium on Uranium Plasmas, July 1976; also published as: Partially Ionized and Uranium Plasmas, NASA publication, 1976.

3) M. Garcia, G. K. Bienkowski, "The Electron Energy Distribution Function in Electrically Excited Molecular Gases," 28th Gaseous Electronics Conference, in Rolla, Missouri, October 1975.

4) I am grateful to Dr. Britton Chang of LLNL for his suggestions on this point.

5) M. Garcia, B. Chang, "Analytical Boltzmann Moments for Electrons in $\mathrm{N}_{2}-\mathrm{O}_{2}-\mathrm{H}_{2} \mathrm{O}$ Gas Mixtures," IEEE International Conference on Plasma Science, at Santa Fe, NM, June 6-8, 1994. 